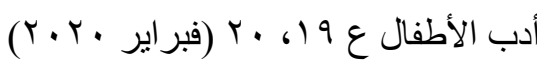
ظاهرة عمالة الأطفال في الخرطوم

\title{
ظاهرة عمالة الأطفال في الخرطوم
}

\section{د. نهى عبد الله خيرت}

\section{دكتوراه في الأنثروبولوجيا}

\section{معهد البحوث والدراسات الإفريقية}

أقسى شيءٍ في العالم هو رؤية طفلٍ قد غطّى وجهه الضغوط والإحباط والتمرد و الاستياء من المجتمع وكل من حوله، السبب الرئيس في هذه الحالة هو الوصول إلى سوق هو

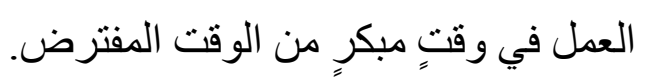

ظاهرة عمالة الأطفال منتشرة في جميع أنحاء العالم ولا تقتصر على المجتمعات النامية أو الفقيرة وما يرتبط بها من آثارٍ على التتمية الاقتصادية والاجتماعية والسياسية و الثقافية، ومع الانتشار السريع لهذه الظاهرة زادت المخاوف الدولية من وجودها وانتشار ها ومحاولة القضاء عليها بطرقٍ مختلفة. تحتفل المنظمات والحكومات الدولية في 11 يونيو من كل عام باليوم العالمي لمكافحة ظاهرة "عمالة الأطفال". هنالك العديد من الدراسات التي أُجريت لتوضيح ظاهرة عمالة الأطفال في دول العالم ككل، سواء أكانت غربية أم عربية، ومن بين الدراسات التي أُجريت في القارة الآسيوية، در اسة حول ظاهرة عمالة الأطفال في الهند، حيث أظهرت الدراسة أن غالبية الأطفال العاملين في الهند ينتمون إلى الطبقات الأكثر فقرًا، ويرجع ذلك إلى طبيعة تركيب المجتمع الهندي، وفي أوائل العشرينيات وُجدَ أن عمالة الأطفال مناسبة في مجالات التصدير، حيث أوضحت الدراسة أن هنالك أطفالاً تقل أعمار هم عن خمس سنواتٍ يعملون من السادسة صباحًا وحتى السابعة مساءً ويتقاضون أقل من • ب سنتًا.

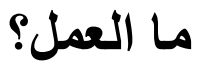

في البداية، يجب أن نشير إلى أن مصطلح "عمالة الأطفال" لا يشمل كل الأعمال التي يمارسها الأطفال دون سن التامنة عشرة، فهناك العديد من المهن والأعمال التي يمارسها الأطفال بصورةٍ شرعية سواء كانت تلك الأعمال مدفوعة الأجر أو غير مدفوعة الأجر، وتتوافق هذه الأعمال غالبًا مع عمر الأطفال ومستوى نموهم، كما أنها تعمل على الى اله اكتسابهم العديد من المهار ات، إلى جانب تحملهم أيضًا المسئولية، وبالتالى تعمل على زيادة دخل أسرهم، ومن هذه الأعمال: العمل الذي يقوم به الأطفال بعد عودتهم من المدرسة، أو 


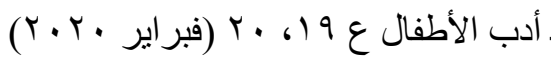
ظاهرة عمالة الأطفال في الخرطوم بعد الانتهاء من الواجبات المدرسية ولا يدخل في نطاق عمل الأطفال، وهذا العمل هو

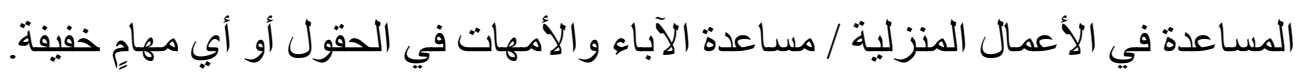

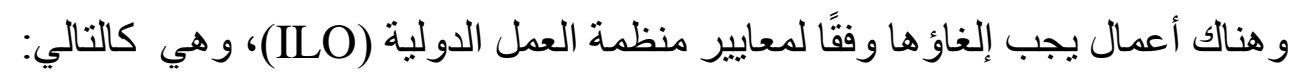

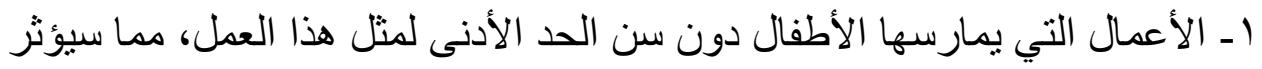
على نمو الأطفال ويوقف استكمال تعليمهر. r ـ الأعمال التي من شأنها أن تؤثر على سلامة الطفل جسديَّا وعقليًا ونفسيًّا ومعنويًّا؛ إما بسبب طبيعتها، أو بسبب الظروف التي يتم خلالها هذه الأعمال. بمعنى آخر :

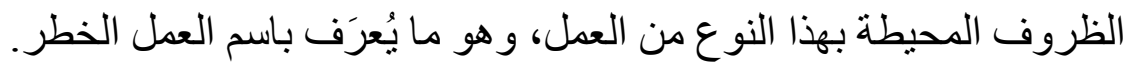

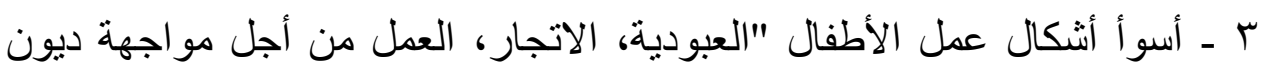

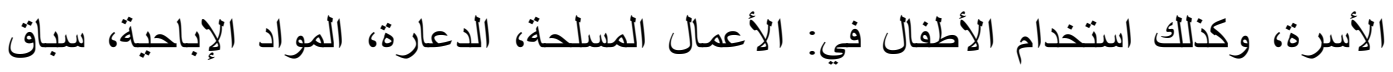

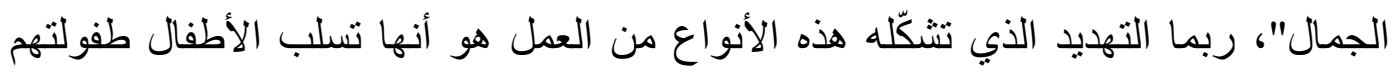

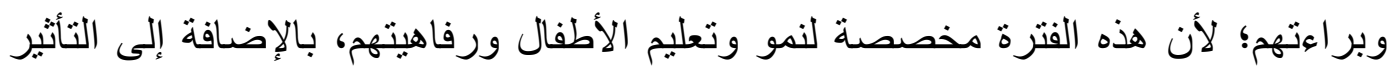
السلبي على صحتهم و على نفسيتهم وتطور هم، وربما أخطر عمل هو الذي يتسبب في تغيير

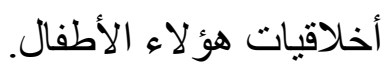

\section{ما أسوأ أشكال عمل الأطفال؟}

تعرف منظمة العمل الدولية (ILO) أسوأ أنثكال عمل الأطفال على أنها أكثر الأعمال تدميرًا، وهي تهدف إلى إلحاق الضرر وترتبط بصحة الأطفال؛ لأنهم يمارسونها

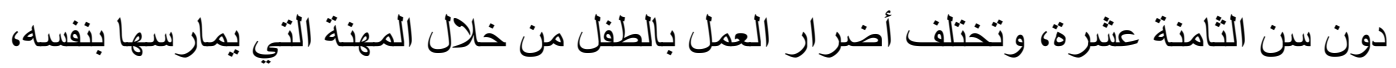

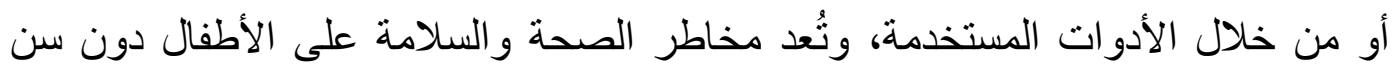

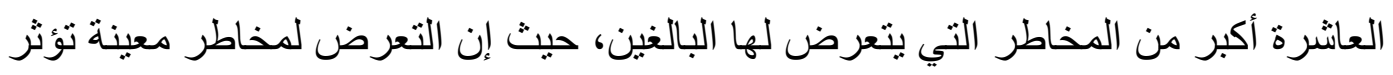

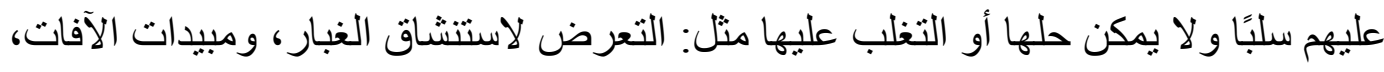

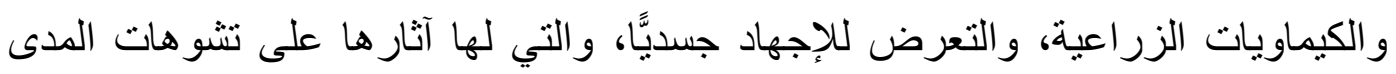
الطويل في الأطر اف أو العمود الفقري و لا يمكن علاجها في المستقبل.

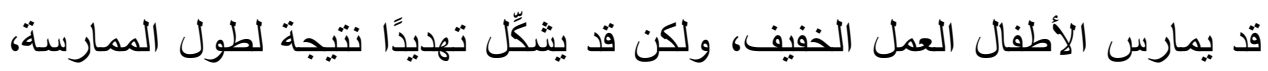

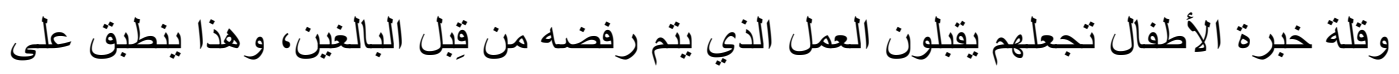

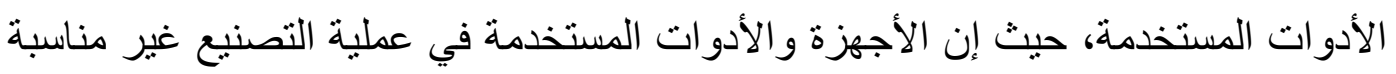
للاستخدام من قِبل الأطفال، كما أن هناك مخاطر قد تبدو بسيطة وغير ضارة، ولكنها في 


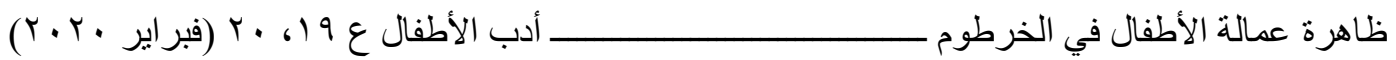
الو اقع ضـارة (كما هي مكثوفة) لأشعة الثمس لفتراتٍ طويلة أثناء الزر اعة، أو أثناء العناية بالماشية، أو التعرض للمو اد الكيميائية الزر اعية، وما إلى ذلك.

و السؤال الذي يتبادر إلى الذهن: ما الذي يدفع الآباء لإنزال أطفالهم إلى سوق العمل على الرغم من أن الحقيقة هي أن الأبوين كل اهتمامهما موجه لمصلحة أطفالهم ومستقبلهج

\section{إذن السبب وراء إلحاق أطفالهما بسوق العمل هو نتيجة لما يلي:}

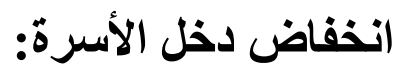

ركزت معظم الدراسات والمؤسسات ووسائل الإعلام على الآثار السلبية لظاهرة

عمالة الأطفال، كما شددت على ضرورة القضاء على هذه الظاهرة بقوة القانون وفرْض عقوبات على أرباب العمل، ولكن كل هذه المحاولات فثلت؛ لأن معظم هذه الحلول التي تحاول حل الظاهرة تكون غير كاملة دون الرجوع إلى جذورها ومحاولة القضاء على الأسباب الجذرية لتفاقم هذه الظاهرة، وقد أثبتت معظم الدراسات و الواقع الفعلى أن الأسرة التي تحتاج إلى دعمٍ مالى هي السبب الرئيس لتسرب الأطفال من التعليم، حيث يتم تسجيل هؤلاء الأطفال في سوق العمل لتلبية احتياجات أسرهم، وهذا يعكس الدور الذي تلعبه الأسرة لانخر اط أطفالهم في سوق العمل، ولا شك أن عمل الأطفال في سن مبكرة يؤدي إلى انخفاض رأس المال البشري على المدى الطويل، وسيؤدي إلى تباطؤ النمو الاقتصادي

$$
\text { و الاجتماعي. }
$$

\section{العوامل التي تساعد على زيادة معدل عمالة الأطفال:}

حددت معظم الأبحاث أن السبب الرئيس لعمل الأطفال هو انخفاض مستوى دخل الأسرة، ولكن هنالك عو امل أخرى متضافرة تساعد على هذه الظاهرة، والتي تتداخل وتتفاعل وتلعب نفس الدور الذي يلعبه انخفاض دخل الأسرة، مثل:

أـ التعليم وعمالة الأطفال: - أل

على الرغم من أن عمل الأطفال يرتبط ارتباطًا وثيقًا بالعوامل الاقتصادية، فإنه يرتبط بعو امل أخرى مثل: العو امل الاقتصادية، وليس أقل أهمية منها، مثل التعليم. في ظل وجود نظام تعليمي إلزامي ومتميز، نجد أن هذه الظاهرة أقل وضوحًا؛ لأن أنظمة التعليم الجيدة تساعد في إبقاء الأطفال ورفض جميع أنواع الأعمال، و العكس صحيح. وقد أظهرت الدر اسات أن ظاهرة عمالة الأطفال تعمل على التسرب من التعليم وهو السبب الذي يلي انخفاض دخل الأسرة في تز ايد ظاهرة عمالة الأطفال، حيث دعت معظم 


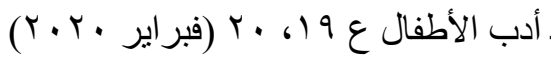
ظاهرة عمالة الأطفال في الخرطوم المنظمات الدولية إلى ضرورة الحدّ من ظاهرة التسرب من التعليم وعمل مشروع يسمى "التكيف الهيكلي"، يهدف إلى الحد من الظاهرة، ولكن واقع الحياة أثبت أن معظم حكومات الدول العربية تسعى إلى الحد من الإنفاق على الجوانب الاجتماعية، مما أدى إلى عدم قدرة الحكومات على توفير أماكن كافية لإيواء هؤلاء الأطفال في المدارس، وكذللك عدم قدرة الأطفال و عائلاتهم على الالتحاق بهذا التعليم بسبب فقر هم، وهذا و اضحٌ في معظم البلدان بما في ذلك السودان، وقد أدى إلى انتنار الأمية بين الأحداث، وخاصة النازحين نتيجة للحروب والمجاعات، وانتشار ظاهرة عمالة الأطفال تحت السن القانوني بدلاً من وجودهم في المدارس.

\section{بـ عمالة الأطفال مدفوعة الأجر ويفضلها صاحب العمل:}

إذا كان السبب الرئيس وراء عمالة الأطفال هو انخفاض دخل الأسرة، فهناك سبب

لا يقل أهمية، وهو أن أصحاب العمل يؤمنون بتشغيل الأطفال لتحقيق منفعةٍ شخصية و أقصى استفادة؛ بسبب ضعف أجور الأطفال مقارنةً بأجور البالغين، وكذلك لأن أجورهم غير خاضعة لقوانين التأمين و المعاشات؛ لعدم بلغوهم السن القانونية للعمل، ويتلقى الأطفال أجورًا متدنية بغض النظر عن ساعات العمل، والتي غالبًا ما تكون أكثر من ساعات العمل القانونية، ومن هنا يتضح لنا أن عمالة الأطفال خطة يدير ها أرباب العمل لتقليل تكلفة الإنتاج

$$
\text { وبالتالى مضاعفة أرباحهم. }
$$

ج- ظاهرة عمالة الأطفال في المجتمعات التي تعاني بالفعل من بطالة البالغين:

أظهرت معظم الدراسات أن المجتمعات التي تهتم بظاهرة عمل الأطفال غالبًا ما

تعاني من ظاهرة بطالة البالغين، وكلما زادت معدلات بطالة البالغين، فإن ذلك سيدفع الآباء العاطلين لإلحاق أطفالهم بسوق العمل تحت ضغط الحاجة والعوز وعدم القدرة على تلبية المطالب الأساسية.

لقد استعنتُ بعينة مكوَّنة من ( • ع ( ) طفلاً؛ لتعبر عن عمالة الأطفال في أماكن ومهن مختلفة مثل: الثوارع، و المصانع، و المو اصلات، والأسواق... إلخ، و هذه العينة تم رصدها في الولايات الثلاث للخرطوم الكبري، وهي: الخرطوم، و الخرطوم بحري، و أم درمان، و إن كانت العينة قليلة ولا تعكس الظاهرة بصورة شاملة، إلا إنها مجرد وسيلة استدلالٍ للتعرف على شكل الظاهرة، خاصة أن الجهات الرسمية لم تستطع رصند الظاهرة بصورة كاملة؛ نظرًا لإنكار أصحاب الأعمال، وكذلك الأطفال ذاتهم خوفًا من المساءلة القانونية، وإن كانت 


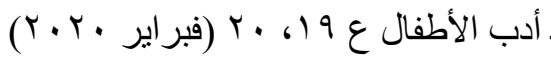
ظاهرة عمالة الأطفال في الخرطوم هذه العينة تناولت معظم جو انب حياة الطفل سواء داخل أسرته أو في بيئة عمله.... إلخ،

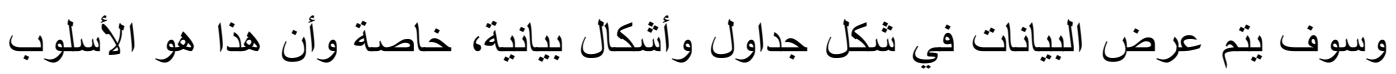
المتبع في معظم الدراسات التي اطلعتُ عليها، وهي تعكس حجم الظاهرة وشكلها من خلال

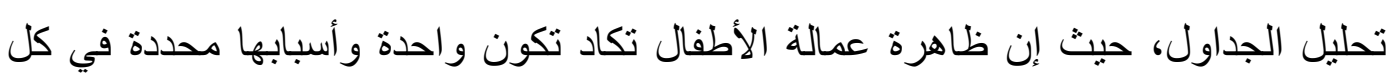

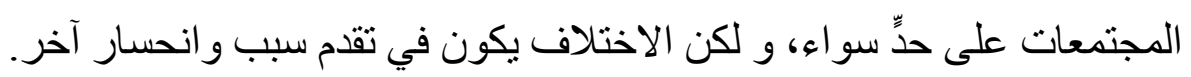
وسوف تنقسم الجداول إلى ثلاثة أجزاء: الجزء الأول: يحوي البيانات الثخدية

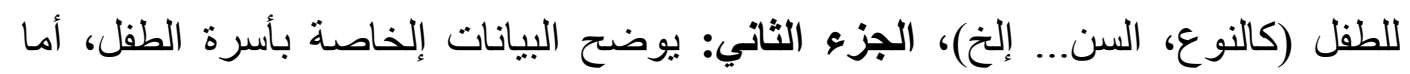
الجزء الأخير، فهو الذي ينعرض للطفل في محيط العمل.

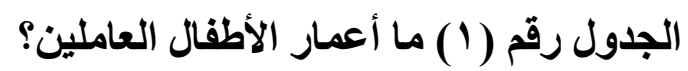

\begin{tabular}{|c|c|c|}
\hline النسبة المئوية & عدد الأطفال & الفئة العمرية \\
\hline rq & rk & 11.0 \\
\hline TI & $\varepsilon r$ & $\mid r-11$ \\
\hline ז & $\varepsilon V$ & 10.14 \\
\hline 9 & Ir & $1 \Lambda_{-10}$ \\
\hline$\% 1 \ldots$ & $1 \varepsilon$. & المجموع \\
\hline
\end{tabular}

نجد أن نسبة الأطفال العاملين في الفئة العمرية (0 : • 1) بلغت بr\% من حجم

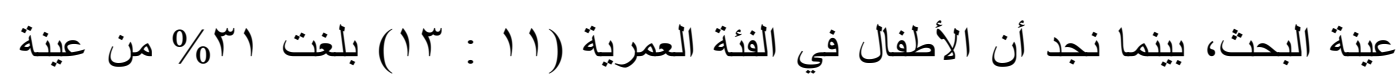

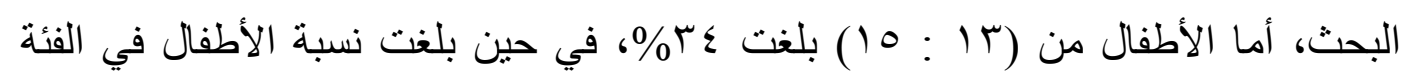

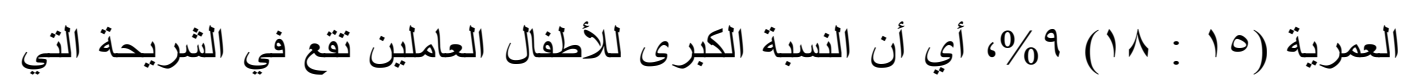

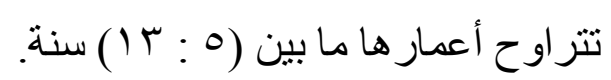

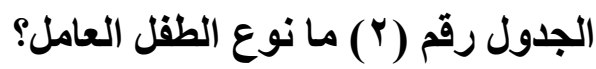

\begin{tabular}{|c|c|c|}
\hline المئوية & عدد الأطفال & النوع \\
\hline$V \psi$ & $1 . r$ & ذكور \\
\hline$r V$ & rर & إناث \\
\hline$\% 1 \ldots$ & $1 \leqslant$. & المجموع \\
\hline
\end{tabular}




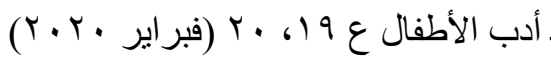
ظاهرة عمالة الأطفال في الخرطوم بلغ عدد الأطفال الذكور في عينة البحث بr\% من إجمالّى حجم العينة، في حين بلغ عدد الإناث YY\%، ولعل ذللك سببه أن مجتمع الدراسة ما زال تحكمه وتسوده عادات وقيم ترى أن نزول الفتاة لسوق العمل شيءٌ غير مرغوب وغئ وغير مستحب، سبب آخر لا يقل أهمية عن سابقه وهو أن البيانات المتعلقة بالفتيات العاملات غير دقيقة؛ وذلك لأنها لا نتمل الفتيات التي تعمل ضمن نطاق أسرتها أو التي تعمل في مجال خدمة المنازل، سبب ثالث هو إنكار الأطفال و أسر هم لانخر اط أبنائهم في سوق العمل؛ خشية التعرض للمساءلة أو العقاب.

\section{الجدول رقم (r) ما الحالة التعليمية؟}

\begin{tabular}{|c|c|c|}
\hline النسبة المئوية & عدد الأطفال & الحالة التعليمية \\
\hline YI & rq & أمي \\
\hline$r$. & $r \wedge$ & خلوة \\
\hline$r r$ & $\& 7$ & أساسيى \\
\hline $1 \varepsilon$ & $r$. & فني \\
\hline 0 & V & ثناتوي \\
\hline V & 1. & غير مبين \\
\hline$\% 1 \ldots$ & $1 \varepsilon$. & المجموع \\
\hline
\end{tabular}

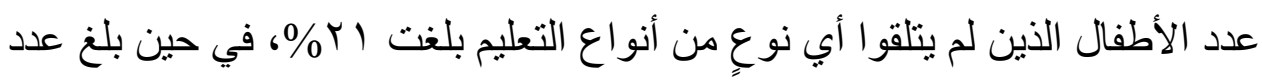

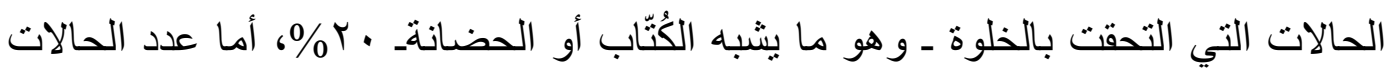

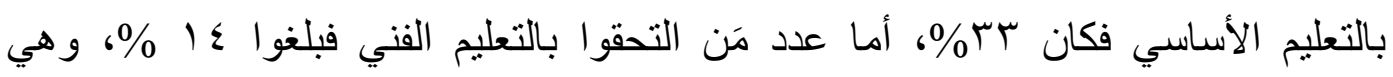
الحالات التي التقيثُ بهم في مركز التدريب الموجود بأم درمان.

ولقد لاحظت أن معظم الملتحقين بالمركز يقومون بالعمل في الفترة التي تلي لني

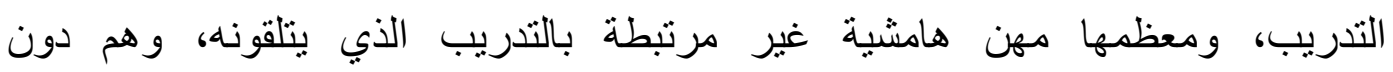

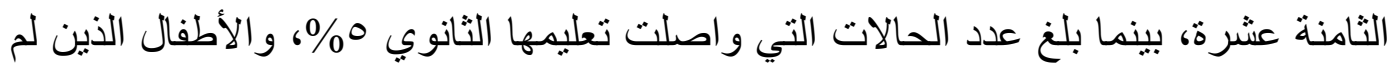

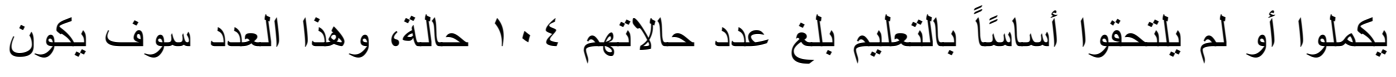

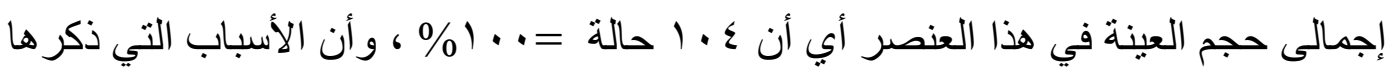

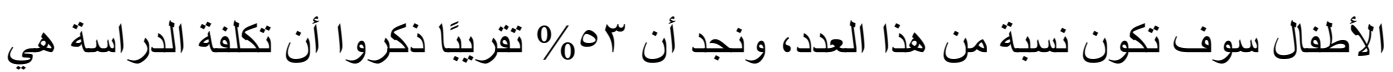

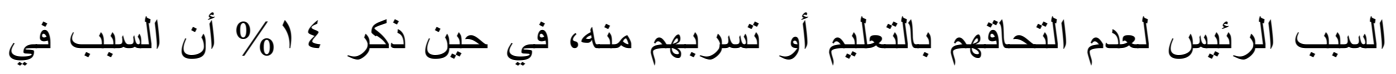




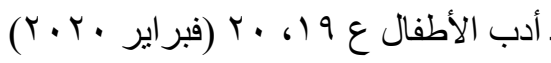
ظاهرة عمالة الأطفال في الخرطوم

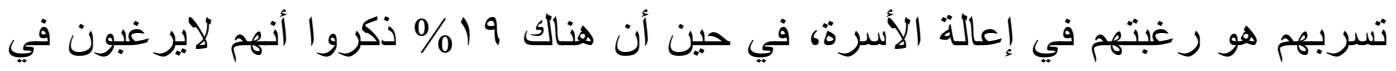

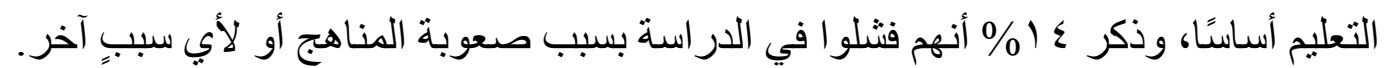

\section{جدول رقم(؛ ) ما أسباب التسرب الدراسي؟}

\begin{tabular}{|c|c|c|}
\hline النسبة المئوية & التكرارأو عدد الأطفال & سبب ترك التعليم \\
\hline or & 00 & تكلفة الدراسةة \\
\hline $1 \varepsilon$ & $1 \varepsilon$ & إعالة الاسرة \\
\hline 19 & $r$. & عدم الرغبة في \\
\hline $1 \varepsilon$ & 10 & فشل دراسي \\
\hline$\% 1 \ldots$ & $1 \cdot \varepsilon$ & المجموع \\
\hline
\end{tabular}

و إذا نظرنا للأسباب السابقة نجد أن VI\% أرجعوا أسباب تسربهم إلى العامل

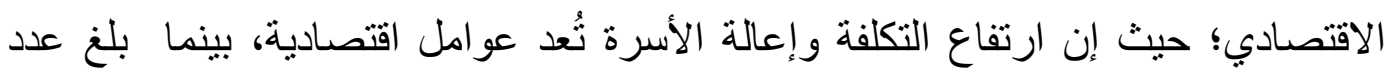

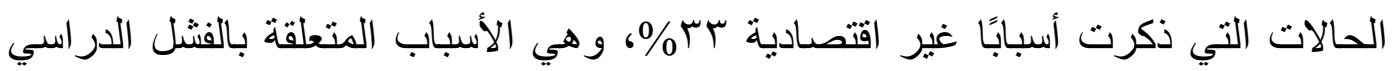
و عدم الرغبة، و هذان العاملان يعكسان عدم وعي الأطفال و أسر هم بقيمة التعليم و أهميته.

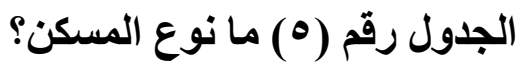

\begin{tabular}{|c|c|c|}
\hline النسبة المئوية & عدد الأطفال & نوع المسكن \\
\hline 18.0 & $1 \varepsilon$ & ملك \\
\hline$\mu$. & $Y \leqslant$ & إيجار منفرد \\
\hline$\varepsilon 0$ & $r q$ & عشوائي \\
\hline$V .0$ & 7 & غير مبين \\
\hline$\% 1 \ldots$ & $\Lambda$. & المجموع \\
\hline
\end{tabular}

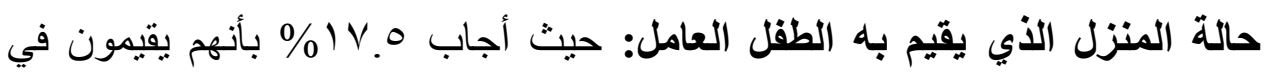

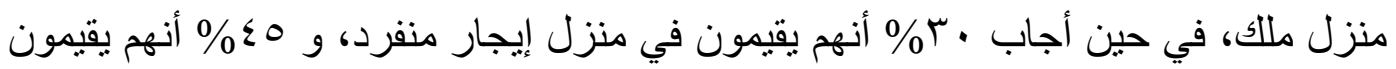

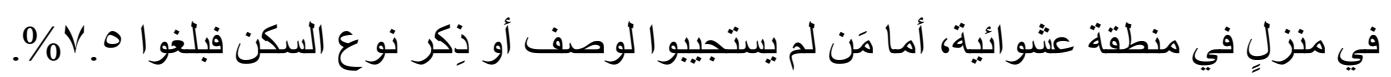

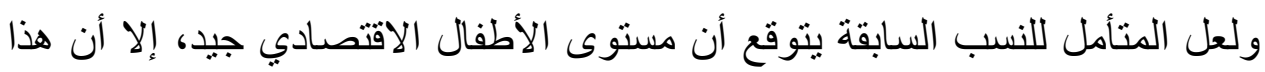

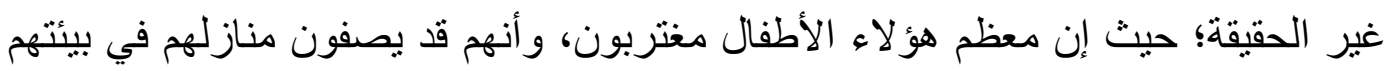

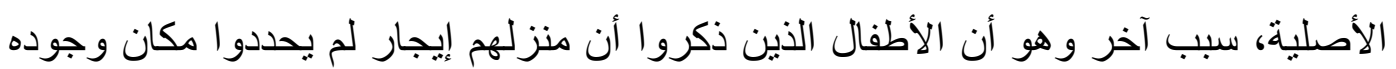




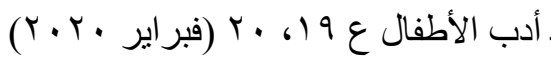
ظاهرة عمالة الأطفال في الخرطوم الذي غالبًا ما يكون في منطقة عشو ائية، سبب ثالث هو إخفاء الأطفال لحقيقة وضعهم حتى لا لا لأل يتم النظر إليهم بصورةٍ متدنية، ومن خلال ملاحظتي غالبًا ما يقيم هؤلاء في المناطق العشو ائية مثل (الحاج يوسف وغير ها من المناطق على أطر اف المدن).

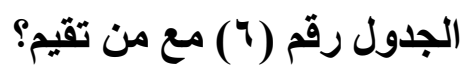

\begin{tabular}{|c|c|c|}
\hline النسبة المئوية & عدد الأطفال & مع من يقيم الطقل \\
\hline $1 \pi$ & 1. & الوالدين \\
\hline ro & r. & أحد الوالدين \\
\hline 1. & $\Lambda$ & الإخوة \\
\hline$r T$ & 11 & أهل غير الوالدين \\
\hline $\mathrm{V}$ & 7 & الأصدقاء \\
\hline 10 & ir & بمفردهم \\
\hline $\mathrm{V}$ & 7 & غير مبين \\
\hline$\% 1 \ldots$ & $\Lambda$. & المجموع \\
\hline
\end{tabular}

مع من يقيم الطفل العامل؟ وقد أجاب سا\% بأنهم يقيمون مع أبويهم، في حين

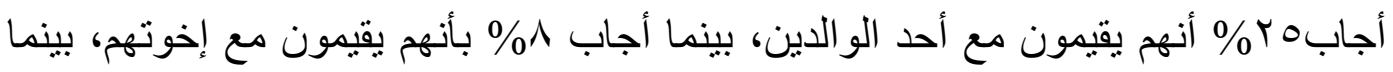

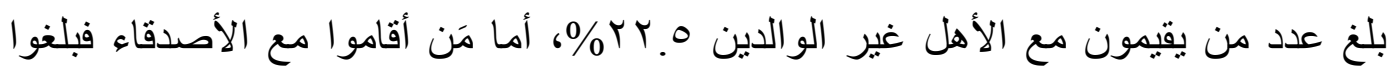

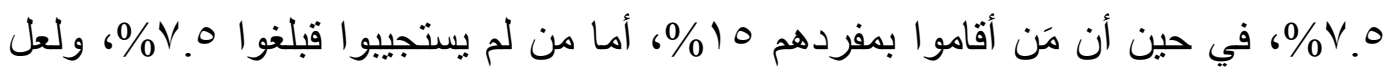

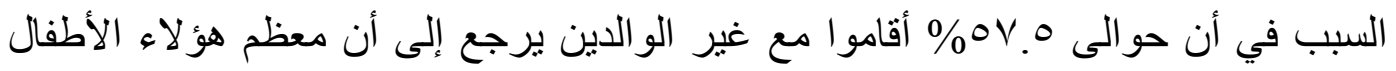
مهاجرين وغالبًا ما يهاجرون بمفردهم إلى الخرطوم، لذا فهم يقيمون مع إخوتهم الذين

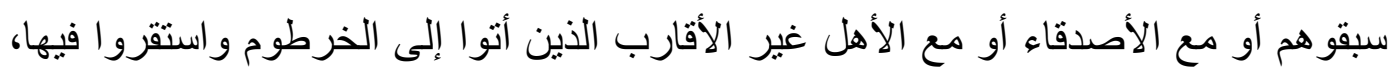

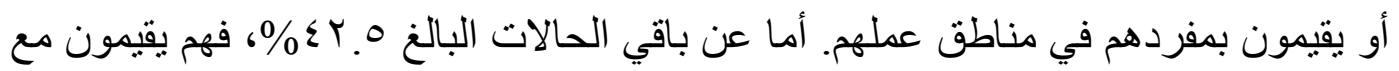

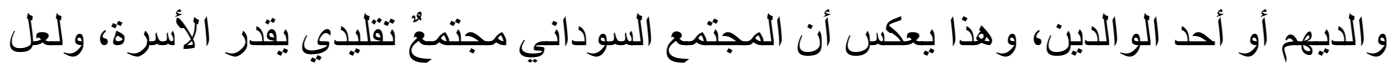
المستجدات التي طرأت على المجتمع من حروبٍ وموجات جفافٍ هي التي دفعت هؤلاء

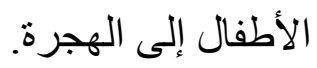

الجدول رقم (V) ما موطنت الأصلي؟

\begin{tabular}{|c|c|c|}
\hline النسبة المئوية & عدد الأطفال & الموطن الأصلي \\
\hline$r \leqslant$ & $r \leqslant$ & الخرطوم وتثثمل: الخرطوم، أم \\
\hline$\sqrt{74}$ & 1.7 & خارج الخرطوم \\
\hline$\% 1 \ldots$ & $1 \leq$. & المجموع \\
\hline
\end{tabular}


موطن أو مولا الأطفال العاملين: حيث أجاب ؟r\% بأنهم ولِدوا وعاشوا في الخرطوم. أما من ولِدوا خارج الخرطوم فبلغوا ج\\%، ولعل السبب في كِبر عدد الأطفال المولودين خارج الخرطوم يرجع إلى استقبالها للعديد من المهاجرين من الجنوب و الغرب؛ بسبب انتشار الحروب في الجنوب وموجات الجفاف في الغرب وهو ما أدى إلى فرار العديد من الأفر ادو الأسر خوفًا من الإيذاء نتيجة الحروب أو الهلاك نتيجة الجفاف. الجدول رقم (^) هل يعمل الأب أو الأم؟

\begin{tabular}{|c|c|c|}
\hline النسبة المئوية & عدد الأطفال & هل يعمل الوالدان \\
\hline$r V_{.0}$ & $r$. & الأب يعمل \\
\hline ro & $r$. & الأم تعمل \\
\hline 10 & Ir & الأب لا يعمل \\
\hline YY.O & 11 & الأم لا تعمل \\
\hline$\% 1 \ldots$ & $\Lambda$. & المجموع \\
\hline
\end{tabular}

مدى عمل الأب والأم من عدمه: حيث أجابه \% \% بأن آباءهم يعملون، بينما أجاب 0\%\% بأن أمهاتهم تعمل، بينما جاءت إجابة 0 \%\% أن آباءهم لا يعملون، أما عدد الذين

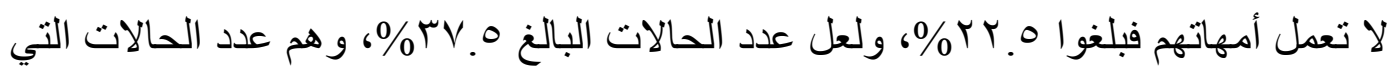
ذكرت أن لا الأب و لا الأم يعملان. ومن الممكن أن نرجع ذلك إلى أن معظم هؤلاء الأسر مهاجرة و أقاموا على أطراف المدن، وفي الغالب لا يتقن هؤلاء الأفراد مهارات تؤهلهم للعمل، و إن كانو ا يملكون مهار اتٍ فهي غالبًا لا تو افق الأوضاع في المدينة، أو بمعنى آخر لا تلائم الحياة المدنية.

\section{الجدول رقم (9) هل يقيم الوالدان معًا؟}

\begin{tabular}{|c|c|c|}
\hline النسبة المئوية & عدد الأطفال & هل يقيم الوالدان معًا \\
\hline$Y V .0$ & rY & نعم \\
\hline VY.O & $0 \wedge$ & $\gamma$ \\
\hline$\% 1 \ldots$ & $\Lambda$. & المجموع \\
\hline
\end{tabular}

أما إذا كان آباء وأمهات الأطفال العاملين يقيمون معًا أم لا: أجابه. YV \% بأنهم يعيشون في كنف أسرةٍ مستقرة بها الأب والأم معًا، بينما جاءت إجابة ه.\%Y أنهم يعيشون 


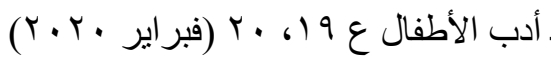
ظاهرة عمالة الأطفال في الخرطوم

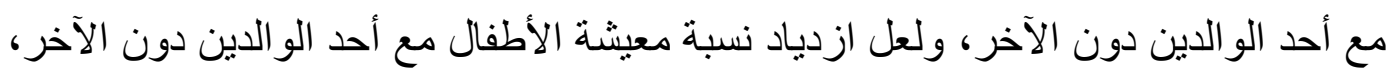

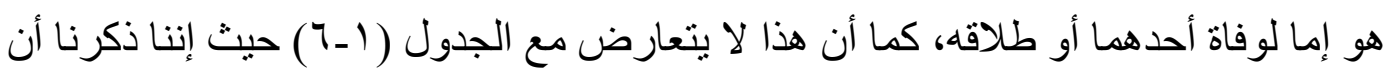

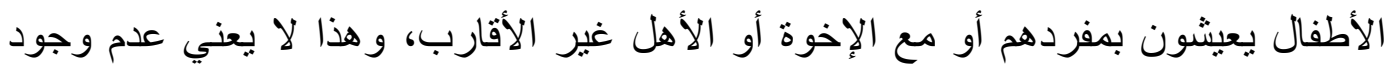

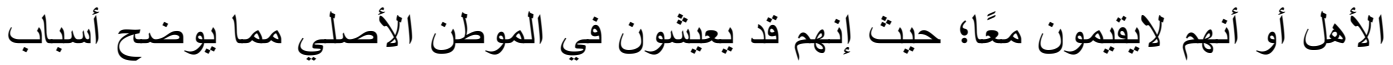
عدم إقامة آباء وأمهات الأطفال معًا. الجدول رقم (• (1) ما أسباب عدم إقامة الأب و الأم معًا؟

\begin{tabular}{|c|c|c|}
\hline النسبة المئوية & عدد الأطفال & اسباب عدم الإقامة \\
\hline$\leqslant 7$ & YO & أحدهما متوفي \\
\hline$r \wedge$ & 10 & مطلقان \\
\hline 11.0 & 1. & متزوج من أخرى \\
\hline V.o & $\varepsilon$ & غير مبين \\
\hline$\% 1 \ldots$ & $0 \leqslant$ & المجموع \\
\hline
\end{tabular}

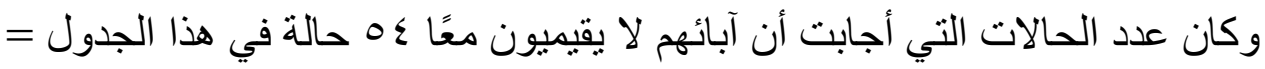

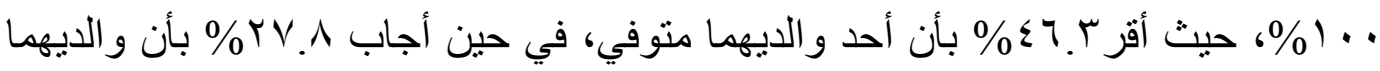

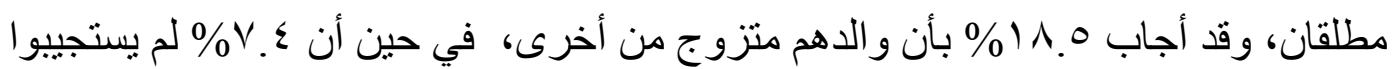

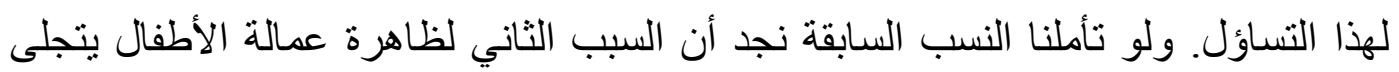
بوضوح، وهو العلاقات الأسرية غير المستقرة. فبالرغم أنتاسبق وذكرنا أن السودان ما زال

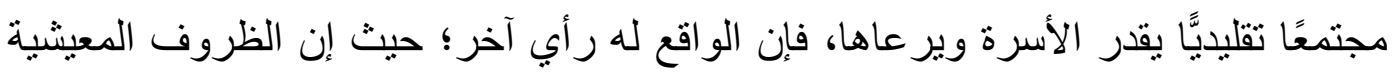
الصعبة و الهجرة والإقامة على أطر اف المدن وتغير نمط الحياة وعدم وجود وظائف لأغلب

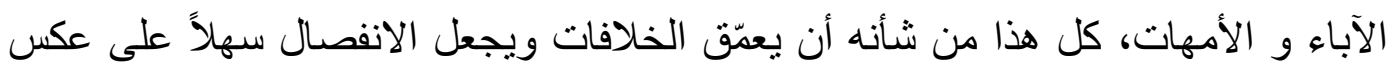

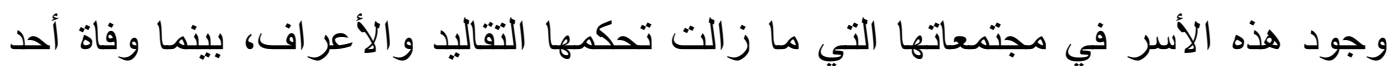
الو الدين له أسباب عدة: كالحروب وموجات الجفاف... إلخ. الجدول رقم (11) - الجم عدد الإخوة والأخوات؟

\begin{tabular}{|c|c|c|}
\hline النسبة المئوية & عدد الأطفال & عدد الإخوة و الأخوات \\
\hline r. & Y $\varepsilon$ & $r-1$ \\
\hline OV & $\{7$ & $7-\varepsilon$ \\
\hline 14 & 1. & 7 فما فوق \\
\hline$\% 1 \ldots$ & $\Lambda$. & المجموع \\
\hline
\end{tabular}




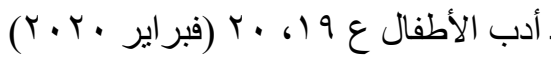
ظاهرة عمالة الأطفال في الخرطوم

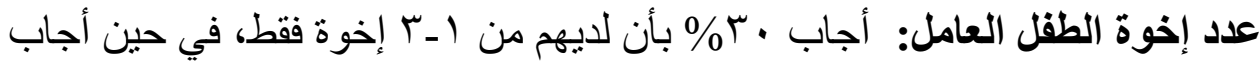

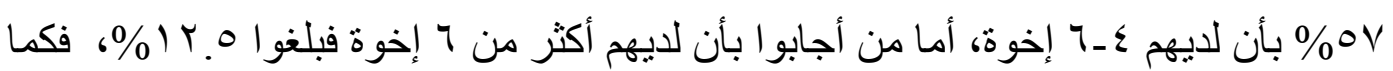

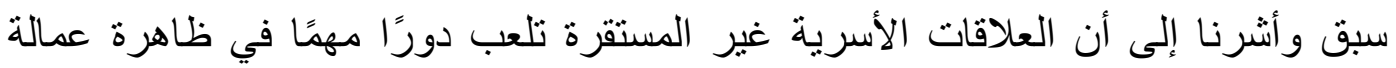

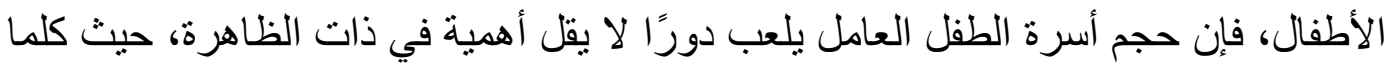

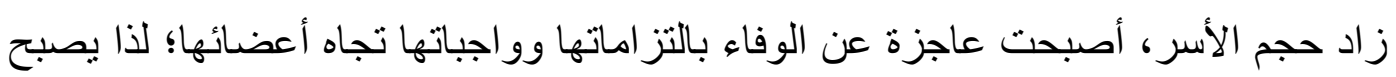

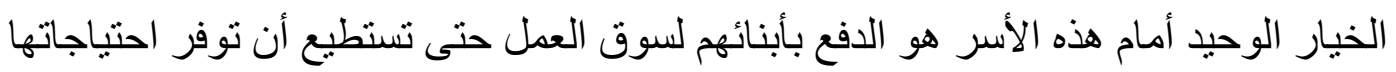

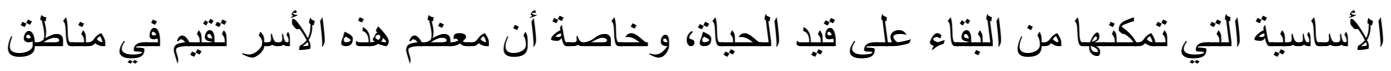
هامثية لا يوجد بها مستوى معيثي جيد.

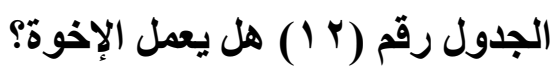

\begin{tabular}{|c|c|c|}
\hline النسبة المئوية & عدد الأطفال & هل يعمل الإخوة؟ \\
\hline rYرo & rq & نعم \\
\hline IV & $0 \leqslant$ & $\gamma$ \\
\hline$\% 1 \ldots$ & $\Lambda$. & المجموع \\
\hline
\end{tabular}

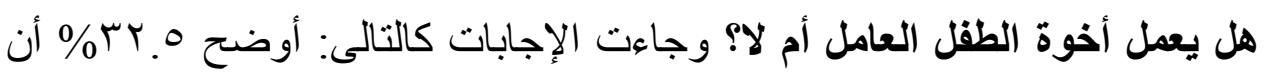

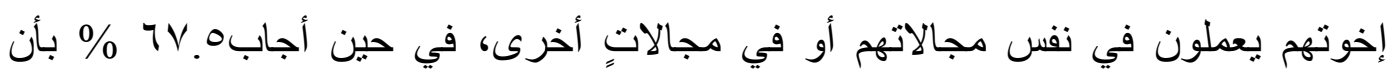

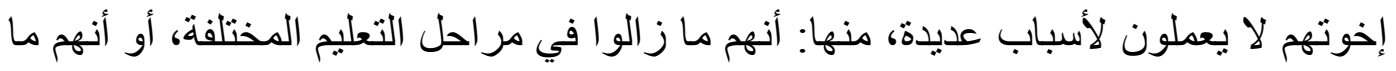
زالو إنغارًا، أو لأنهم يساعدون آبائهم في الأعمال المنزلية... إلخ.

الجدول رقم (ب ا ) ما الحالة الاقتصادية للأسرة؟

\begin{tabular}{|c|c|c|}
\hline النسبة المئوية & عدد الأطفال & الحالة الاقتصادية \\
\hline $1 Y .0$ & 1. & جيدة \\
\hline YY.O & 11 & متوسطة \\
\hline 70 & $O r$ & فقيرة \\
\hline$\% 1 \ldots$ & $\Lambda$. & المجموع \\
\hline
\end{tabular}

الحالة الاقتصادية للأسرة: حيث جاءت إجابة ه.r\% بأن المستوى الاقتصادي

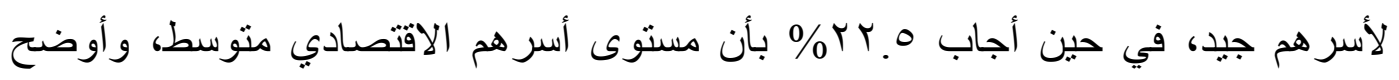

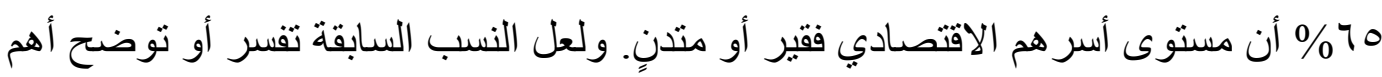

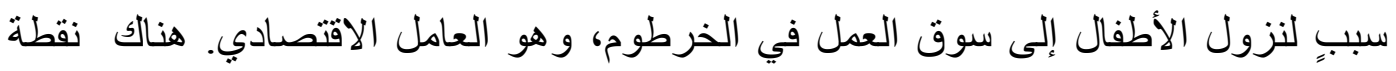




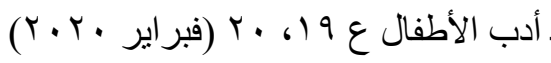
ظاهرة عمالة الأطفال في الخرطوم أخرى مهمة، وهي إجابة 0ب\% بأن أسر هم تحيا في مستوى جيدٍ أو متوسط، ويجب أن ننظر

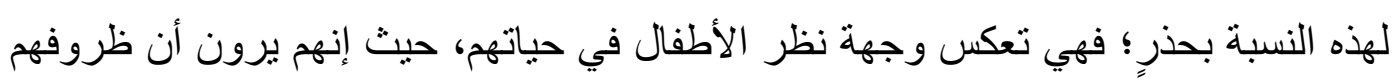

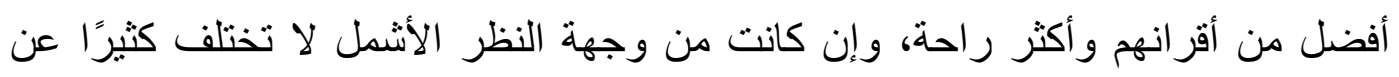

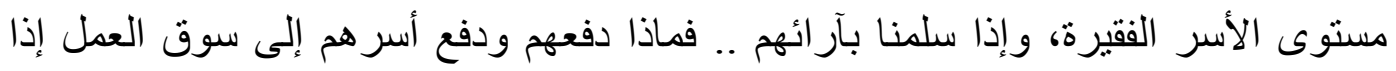

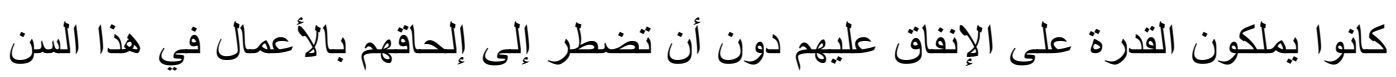

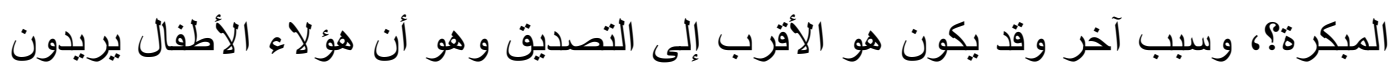
بتلك الطريقة أن يحسّنو ا من صورتهم أمام المجتمع.

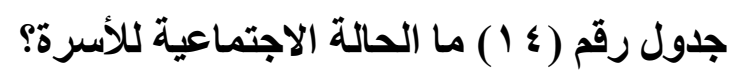

\begin{tabular}{|c|c|c|}
\hline النسبة المئوية & عدد الأطفال & الحالة الاجتماعية \\
\hline 0. & «. & مشاكل أسرية \\
\hline$r$. & $r \xi$ & مشاكل بين الإخوة \\
\hline r. & 17 & لا يوجل \\
\hline$\% 1 \ldots$ & A. & المجموع \\
\hline
\end{tabular}

الحالة الاجتماعية لأسرة الطقل العامل: حيث أجاب .0\% بأن الأسر التي يعيشون

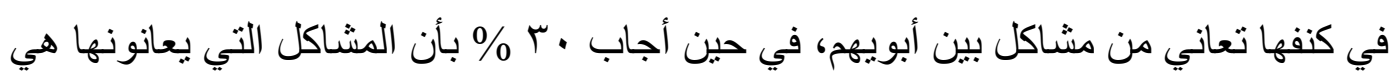

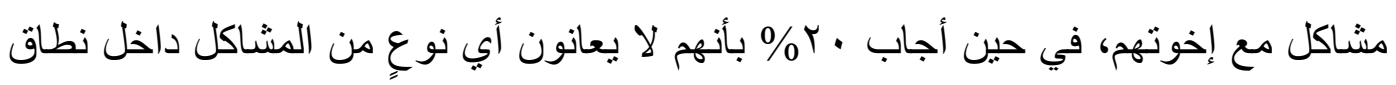

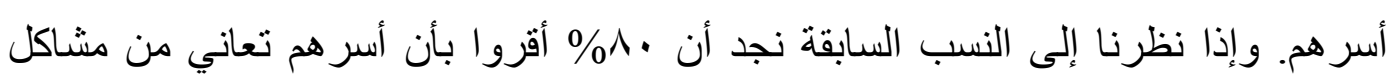

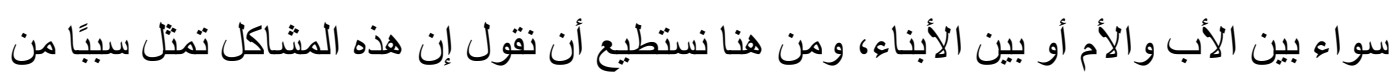

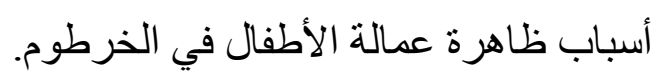

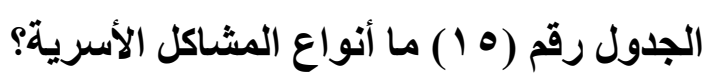

\begin{tabular}{|c|c|c|}
\hline النسبة المئوية & عدد الأطفال & أنواع المشـاكل \\
\hline$\varepsilon \varepsilon$ & rA & الطلاق \\
\hline$\Lambda$ & 0 & زواج الوالدين من آخرين \\
\hline 11 & $\bar{v}$ & خلافَات بين الوالدين \\
\hline$r v$ & $Y \varepsilon$ & مشاكل الإخوة \\
\hline$\% 1 \ldots$ & $\Lambda$. & المجموع \\
\hline
\end{tabular}

المشاكل التي يعانيها الأطفال العاملين داخل أسرهم: و هو ما اتفقت عليه ؟؟ حالة،

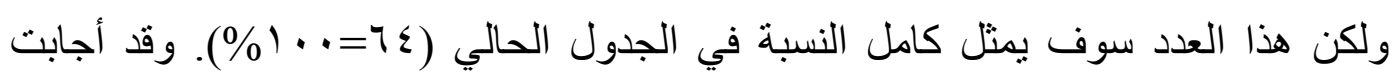




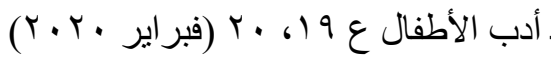
ظاهرة عمالة الأطفال في الخرطوم

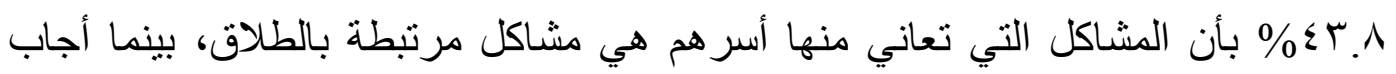

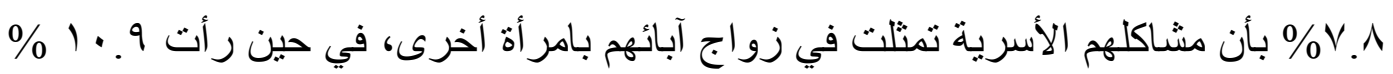

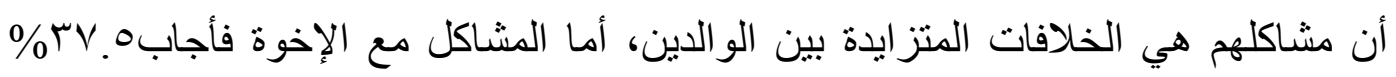

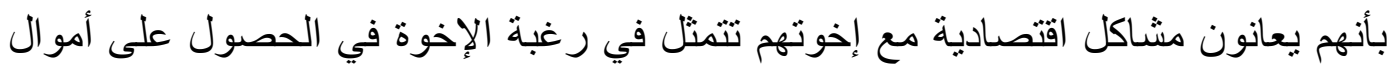

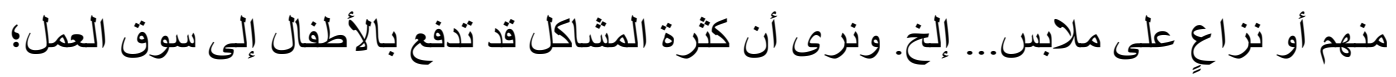

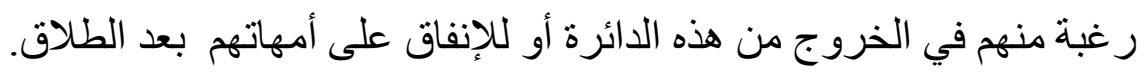

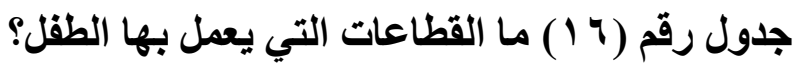

\begin{tabular}{|c|c|c|}
\hline النسبة المئويـة & عدد الأطفال & قطاع العمل \\
\hline 10 & Ir & قطاع الصناعة \\
\hline ro & rA & قطاع التجارة \\
\hline 0 . & $\varepsilon$. & قطاع الخدمات \\
\hline$\% 1 \ldots$ & $\Lambda$. & المجموع \\
\hline
\end{tabular}

قطاعات عمل الأطفال والتي تترواح ما بين العمل في القطاع الصناعي أو التجاري أو الخدمي: ولقد جاءت الإجابات كالتالى: أوضح 10\% أنهم يعملون في دجال الصناعة،

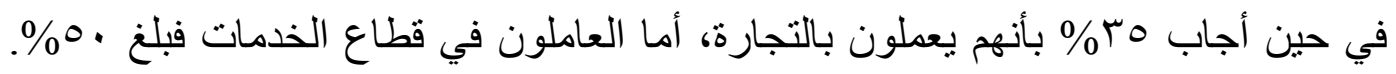

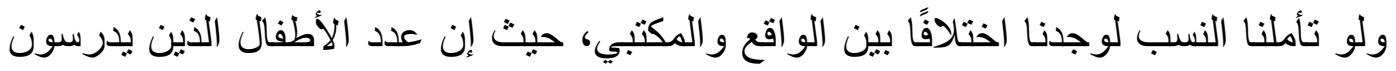

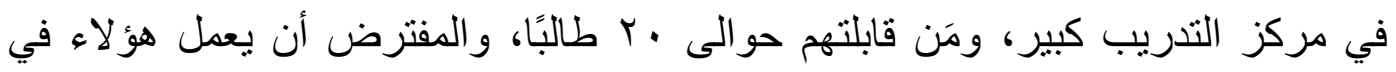

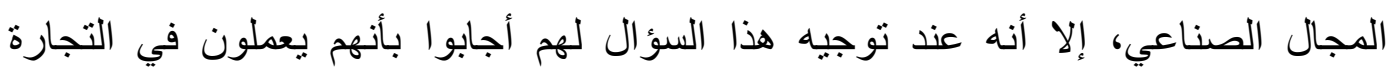

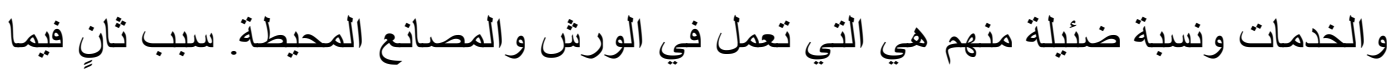

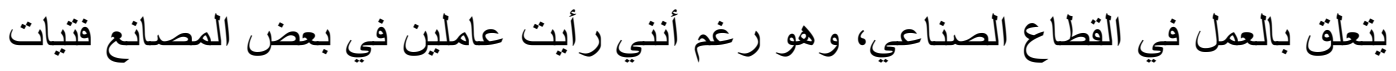

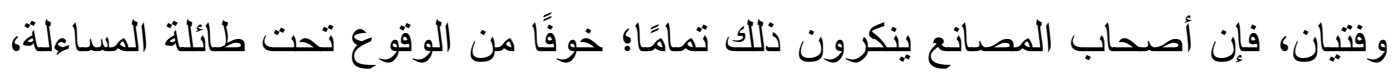

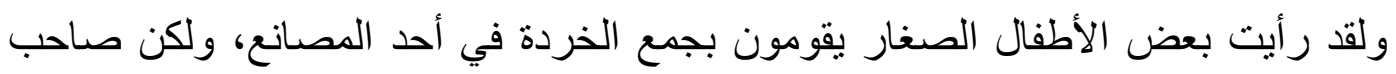

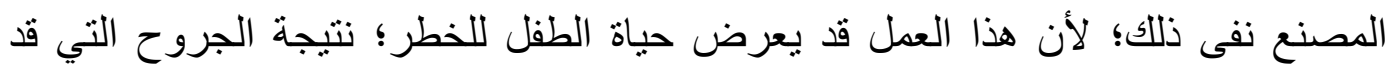

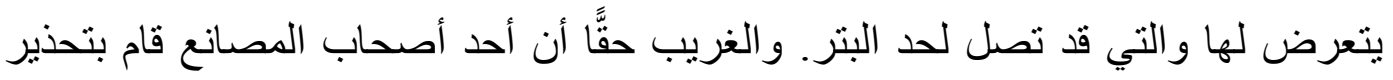

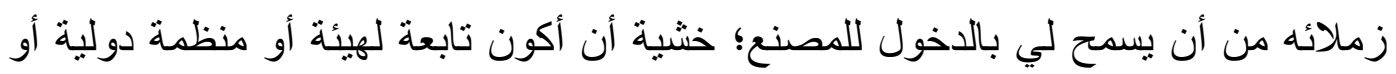

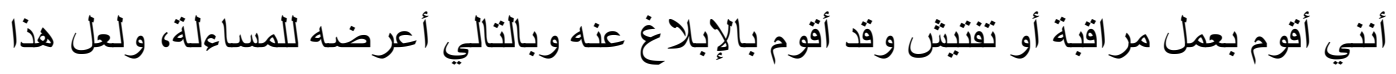
سبب رئيس في عدم الوقوف على الظاهرة بشكلٍ كامل؛ حيث إن هناك أزمة ثقة بين القائمين 


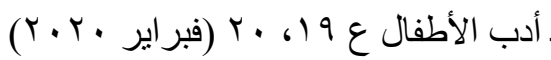
ظاهرة عمالة الأطفال في الخرطوم على حل المشكلة و المشاركين فيها، وبالتالى فإن أي خططٍ يجب أن تُبنى على بياناتٍ و اقعية حتى تؤتي ثمار ها، و هذا لن يحدث إلا عندما تكون هناك ثقة بين طرفي المشكلة، وأن يتم اجتذاب أصحاب الأعمال باللين وليس بالعقاب؛ لآن ذلك سوف يعود بالفائدة على كافة الأطر اف، وسوف يؤدي إلى نتائج و اقعية وفعَّالة. جدول رقم (V I ) ما مناطق عمل الأطفال؟

\begin{tabular}{|c|c|c|}
\hline النسبة المئوية & عدد الأطفال & مناطق العمل \\
\hline 10 & Ir & المنطقة الصناعية \\
\hline ro & $r \wedge$ & السوق والثشارع \\
\hline 0 . & «. & خدمات الثوارع والمنازل \\
\hline$\% 1 \ldots$ & $\Lambda$. & 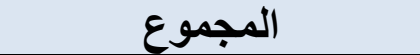 \\
\hline
\end{tabular}

عمل الأطفال: حيث أجاب 10\% بأنهم يعملون داخل المنطقة الصناعية في الورش

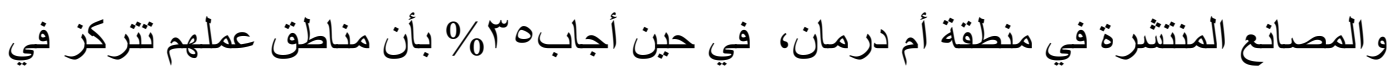

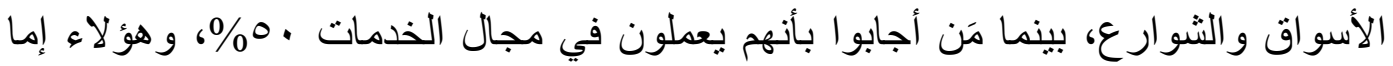

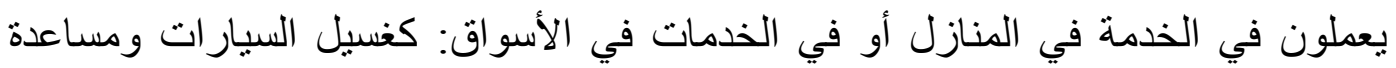

$$
\text { بائعات الأطعمة و المشروبات في السوق.... إلخ. }
$$

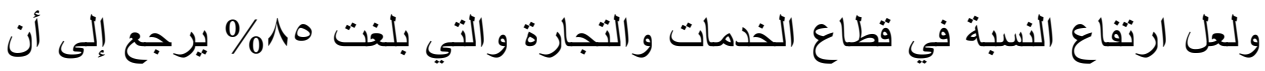

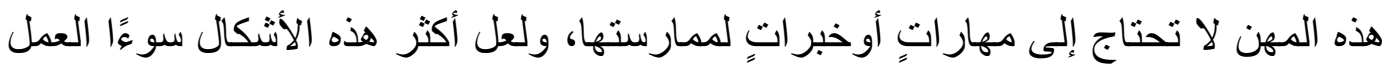

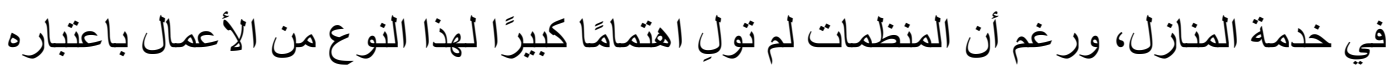
عملاً آمنًا، فإن خطورة هذا النوع تكمن في سريته و أنه مستتر لا يمكن مر اقبته، و لا يمكن معرفة مدى الإيذاء الذي قد يتعرض له الطفل في هذا من اعتداء بدني ومعنوي.

جدول رقم (1 1 ) مَن قام باتخاذ قرار عمل الطقل؟

\begin{tabular}{|c|c|c|}
\hline النسبة المئوية & عدد الأطفال & متخذ قرار العمل \\
\hline r. & 17 & أحد الوالدين \\
\hline YV.O & TY & الأقارب \\
\hline OY.o & $\varepsilon Y$ & الطقل بمفرده \\
\hline$\% 1 \ldots$ & $\Lambda$. & المجموع \\
\hline
\end{tabular}




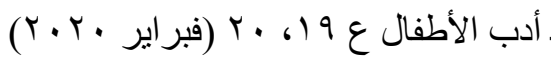
ظاهرة عمالة الأطفال في الخرطوم

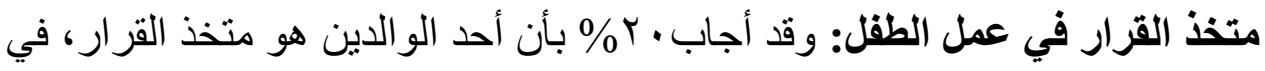

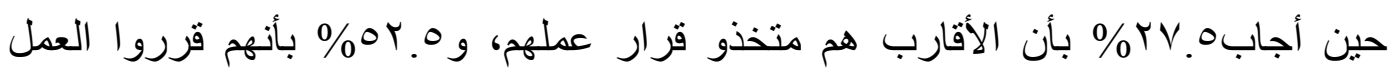

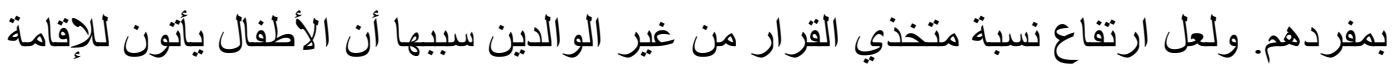

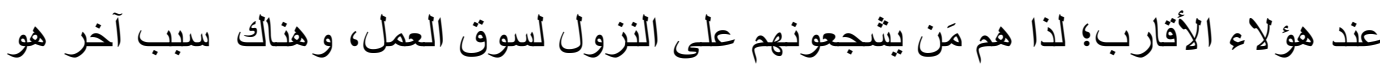

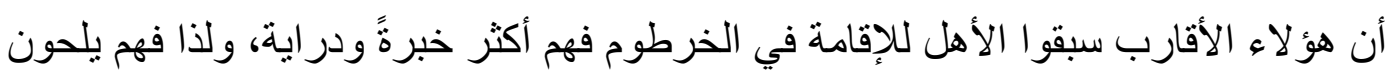
على الأهل لإنز ال أبنائهم لسوق العمل، ويذكرون لهم مز ايا ذللك كجعل الطفل أكثر قدرة على لهاه

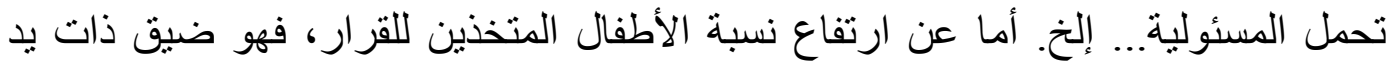
الأسرة مما يجعل هؤلاء الأطفال يشعرون بمسئولية تجاه أسر هم لذا يقررون العمل.

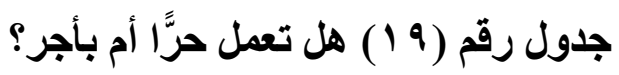

\begin{tabular}{|c|c|c|}
\hline النسبة المئوية & عدد الأطفال & طبيعة العمل \\
\hline MV.0 & $\mu$. & بأجر \\
\hline $7 \% .0$ & 0 . & حــ \\
\hline$\% 1 \ldots$ & $\Lambda$. & المجموع \\
\hline
\end{tabular}

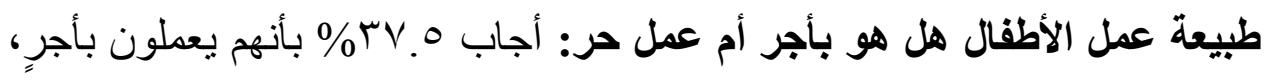

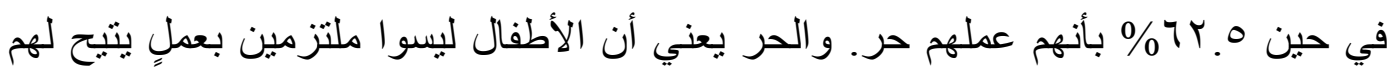

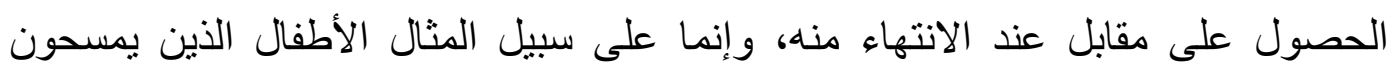
السيارات في الإشارات والأطفال الذين يبيعون المناديل أو البضائع الصغيرة في أماكن

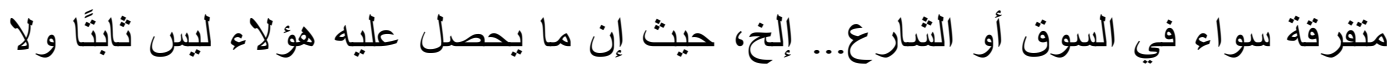

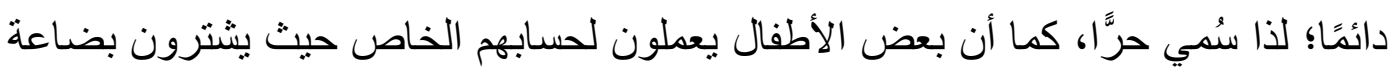
بمبلغ ويقومون ببيعها ويربحون منها، ومن المقابل والربح يقومون بشر اء كمية أكبر وهكذا.

جدول رقم (·ץ) ما طريقة الحصول على الأجر؟

\begin{tabular}{|c|c|c|}
\hline النسبة المئوية & عدد الأطفال & نوعية الأجر \\
\hline 00 & $\varepsilon \varepsilon$ & يومي \\
\hline M.o & Yq & أسبوعي \\
\hline 14.0 & 1. & شهري \\
\hline$\% 1 \ldots$ & $\Lambda$. & المجموع \\
\hline
\end{tabular}




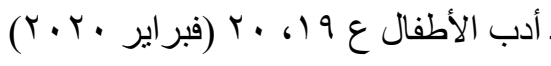
ظاهرة عمالة الأطفال في الخرطوم

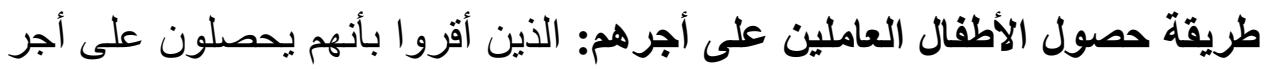

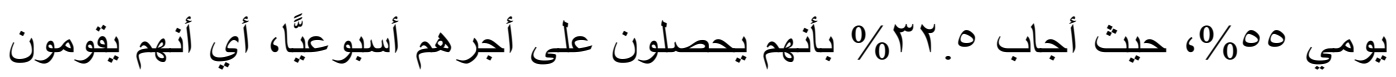

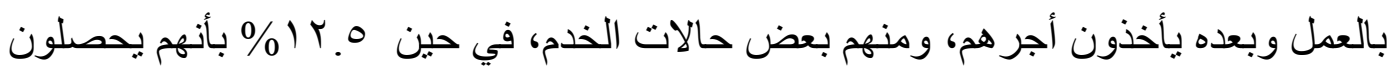

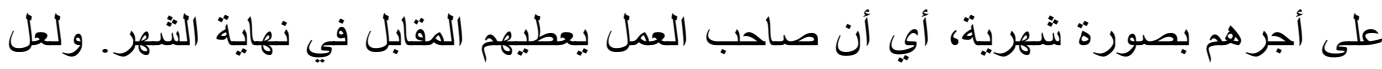

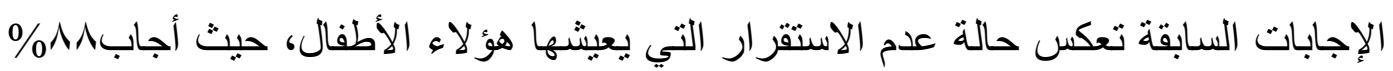

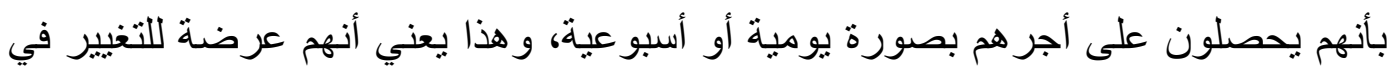

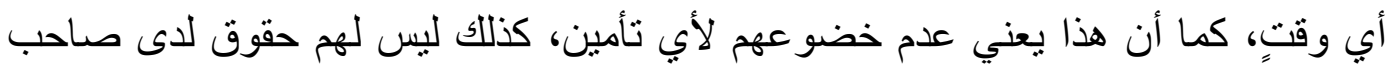
العمل، إلى آخره من مساوئ العمل غير المستقر.

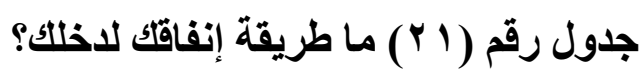

\begin{tabular}{|c|c|c|}
\hline النسبة المئوية & عدد الأطفال & طريقة الإنفاق \\
\hline TY.0 & 0. & للإنفاق على الأسرة \\
\hline ro & $r$. & للإنفاق على ذاتي \\
\hline $1 Y .0$ & 1. & لاستكمال التعليم \\
\hline$\% 1 \ldots$ & A. & المجموع \\
\hline
\end{tabular}

طريقة إنفاق الأطفال للاخل الذي يحصلون عليه بنوعيه: حيث أجاب ه.ب7\% بأن معظم الدخل الذي يحصلون عليه يوجَّه إلى أسر هم كمساهمة في النفقات، في حين بلغ عدد الته

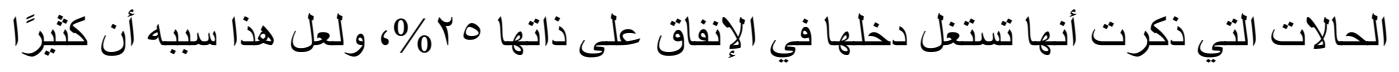

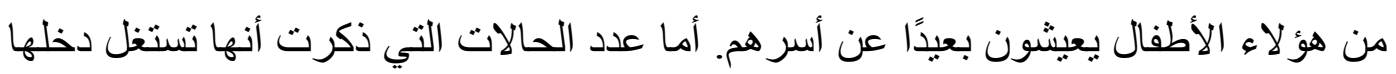

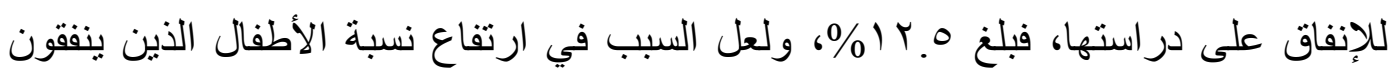

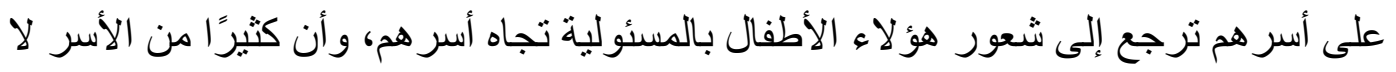
يوجد بها عائل سوى الأم التي غالبًا لا تعمل؛ لذا ينزل الأطفال للعمل للإنفاق على أمهاتهم.

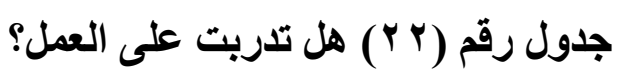

\begin{tabular}{|c|c|c|}
\hline النسبة المئوية & عدد الأطفال & الحصول علي التدريب \\
\hline ro & r. & نعم \\
\hline Vo & 7. & ע \\
\hline$\% 1 \ldots$ & A. & المجموع \\
\hline
\end{tabular}




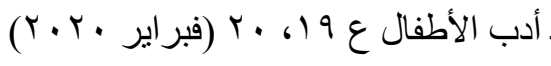
ظاهرة عمالة الأطفال في الخرطوم حصول الأطفال على التدريب من عدمه: أجابه ب\% بأنهم تلقو ا تدريبًا على أعمالهم

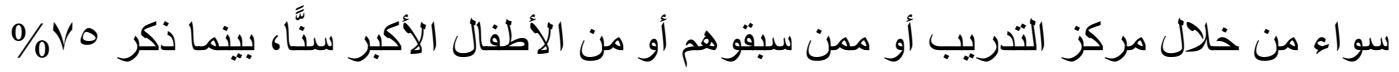
أنهم لم يتلقو ا تدريبًا على المهن التي يقومون بها، ولعل ذللك سببه أن معظم هؤلاء الأطفال يعملون في مهن لا تحتاج إلى مهارة أو تدريب، مثل: بيع المناديل، ومسح الأحذية، ومسح

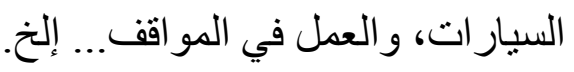

جدول رقم (Yr) هل هناك خطورة من عملك؟

\begin{tabular}{|c|c|c|}
\hline النسبة المئوية & عدد الأطفال & هل توجد خطورة في عملك؟ \\
\hline V० & 7. & نمع \\
\hline ro & $r \cdot$ & $\bar{y}$ \\
\hline$\% 1 \ldots$ & $\Lambda$. & المجموع \\
\hline
\end{tabular}

مدى تعرض الأطفال للخطورة أثناء عملهم من عدمه: حيث أقر \%O بأنهم

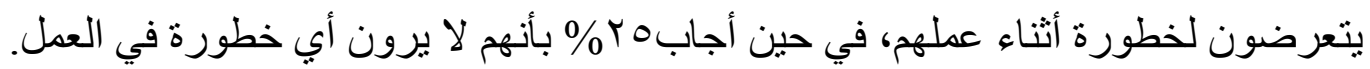

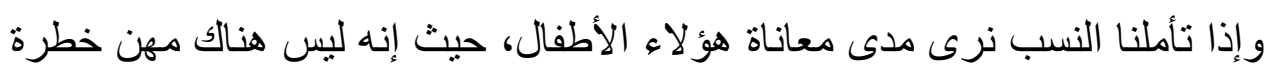
و أخرى غير خطرة، فوجود الطفل في سن صغيرة لمدة طويلة في الثار ع خطر ، وإن كانت

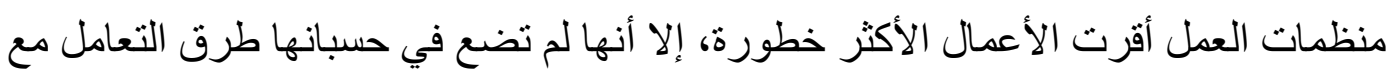

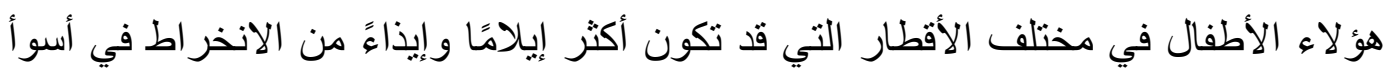
أنتكال العمالة، ولعل هذا كان واضحًا في در اسة "أطفال الهجن"، حيث إن كثيرًا من الأطفال

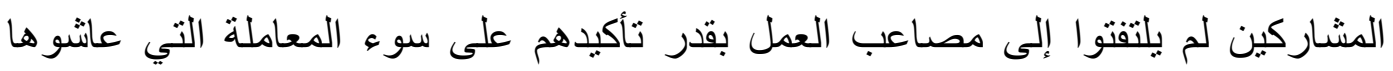

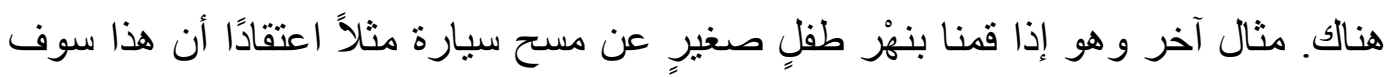

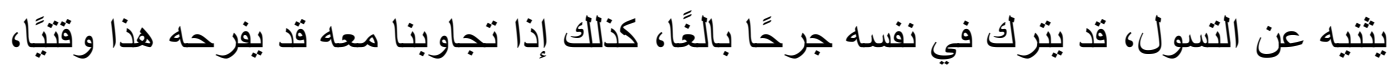

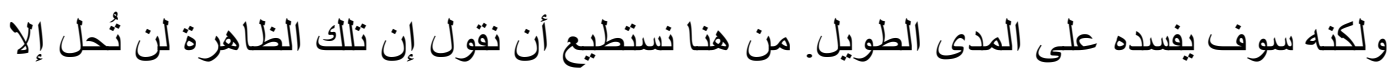
عن طريق الحوار البنَّاء الهادف القابل للتنفيذ، إلى جانب إعداد كو ادر يقع على على عاتقها إدماج لهاج هؤ لاء الأطفال في المجتمع مرة أخرى بصورةٍ سليمة ومدروسة، في حين أن مهنها الأكبر

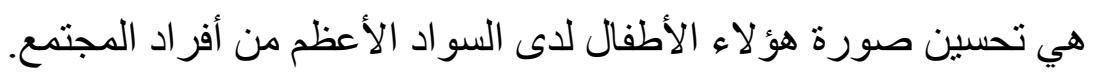




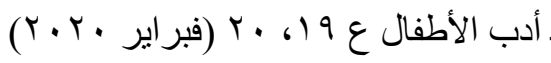
ظاهرة عمالة الأطفال في الخرطوم

جدول رقم (ع Y) ما أنواع الخطورة؟

\begin{tabular}{|c|c|c|}
\hline النسبة المئوية & عدد الأطفال & نوع الخطورة \\
\hline$r \cdot$ & Ir & رفع أشياء ثقيلة \\
\hline$r$. & 11 & التعرض للإصابة والجروح \\
\hline$r$. & Ir & الثمس والحر \\
\hline$r$ & 11 & الحوادث \\
\hline$\% 1 \ldots$ & 7. & المجموع \\
\hline
\end{tabular}

أنواع الخطورة التي يتعرض لها الطفل العامل أثناء عمله: حيث أجابت . 7 حالة بأنهم يتعرضون للخطورة أثناء عملهم، وهذا العدد سوف يصبح هو حجم العينة في هذا

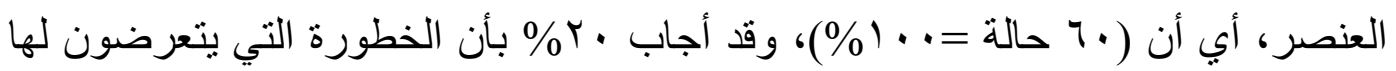

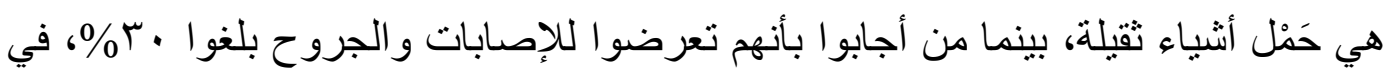
حين أجاب • ץ\% بأن الخطورة تتمثل في تعرضهم للشمس والحرارة العالية، أما من أجابوا

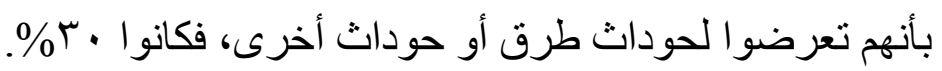
جدول رقم (ب0) هل أنت راضٍ عن عملك؟

\begin{tabular}{|c|c|c|}
\hline النسبة المئوية & عدد الأطفال & راضٍ عن عملك \\
\hline Vo & 7. & نعم \\
\hline Yo & $r$. & $y$ \\
\hline$\% 1 \ldots$ & $\Lambda$. & المجموع \\
\hline
\end{tabular}

مدى رضا الأطفال العاملين عن عملهم من عدمه: أجابه٪\% بأنهم راضون عن عملهم، في حين من أجابوا بأنهم غير راضين بلغوا 0Y\%\%. ولعل الرضا وعدم الرضا من من الأمور النسبية، حيث أقر الأطفال بأنهم راضون، وقد يكون ذلك بسبب حصولهم على أجر يوفر لهم البقاء على قيد الحياة أو أنه يساهم في إعالة أسر هم إلى آخره من الأسباب. أما عدم الرضا، فقد يكون له أسبابٌ أخرى، و هي تعرضهم لمضايقات، أو معاملة الأشخاص لهم، أو عدم وفاء العمل باحتياجاتهم... إلخ. 


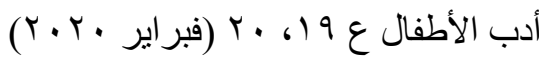
ظاهرة عمالة الأطفال في الخرطوم جدول رقم († Y ) هل تقبل إذا أتيحت للك فرصة لاستكمال تعليمك؟

\begin{tabular}{|c|c|c|}
\hline النسبة المئويةة & عدد الأطفال & فرصة تعليم \\
\hline $7 Y .0$ & 0. & نعم \\
\hline$r V_{.0}$ & r. & $y$ \\
\hline $1 \ldots$ & $\Lambda$. & المجموع \\
\hline
\end{tabular}

هل يقبل الأطفال العاملون الاستمرار في التعليم إذا أتيحت لهم فرصة الانتظام مرة أخرى في الاراسة؟ أجاب ه.ب7\% بأن لايهم الاستعداد لترك العمل والاستمرار في الدر اسة، ولعل هذه الثريحة ترغب في تحسين مستو اها المادي و المعنوي و الارتقاء واحتلال مكانةٍ أفضل، في حين أجاب ه.\%\% بلا، لن نترك العمل من أجل الدراسة، ولعل هذه الشريحة لها مبرر في الاستمرار في العمل؛ وهو الشعور بمسئولية تجاه أسر هم، كذلك أن هذه الثريحة أصبح لديها نوعُ من الاستقلال المادي لن يتنازلو ا عن هذا الأجر نظير الرجوع مرة أخرى للار اسة، وأنهم عقدوا مقارنة بين الأجر الذي يحصلون عليه الآن والأجر الذي سوف يحصلون عليه بعد استكمال دراستهم، فوجدوا هذا أكثر بغض النظر عن نظرة المجتمع واختلاف المكانة، كذلك أن هؤلاء الأطفال يرون ظاهرة البطالة بالنسبة للار اسين في معظم المجالات وبين إخوتهم أو أقاربهم أو المحيطين بهم. جدول رقم (rv) ما العقاب الذي يتلقاه الطقل العامل بأجرٍ من رئيسه؟

\begin{tabular}{|c|c|c|}
\hline النسبة المئوية & عدد الأطفال & تصرف الرئيس \\
\hline$\mu$ & 1. & ضرب \\
\hline$r r$ & $\mathrm{~V}$ & زجر وتوبيخ \\
\hline$r V$ & $\Lambda$ & خصم من الراتب \\
\hline IV & 0 & معاملة حسنة \\
\hline$\% 1 \ldots$ & $r$ & المجموع \\
\hline
\end{tabular}

معاملة رؤساء العمل للأطفال العاملين: ولعل هذه الحالة تتطبق على العاملين بأجر،

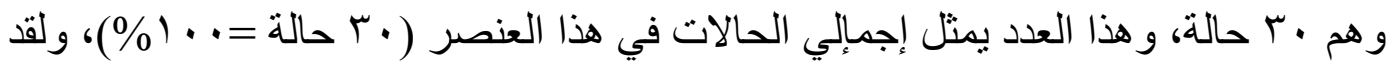
أجاب r.rr\% بأنهم يتعرضون للضرب من قِبل رؤسائهم في العمل، في حين ب.r\%\% بأنهح يتعرضون للزجر أو التوبيخ من قِبل رؤسائهم، بينما أجاب V.Y.\% بأنه يتم خصم جزء من راتبهم نظير أي خطأ يرتكبونه، بينما الذين أجابو ا بأن رؤساءهم يعاملونهم بالحسنى 


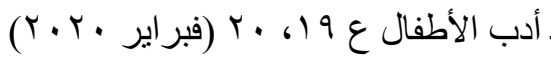
ظاهرة عمالة الأطفال في الخرطوم بلغو ا V.7 (\%). ولعل الإجابات السابقة تعكس الظروف الصعبة التي يعيشها هؤلاء الأطفال، حيث إن عدد الحالات التي أقرت بأنها تخضغ للعقاب عند ارتكابها أي خطأ بلغت ب. س^\%٪. جدول رقم (Y Y ) ما علاقة الطقل بزملائه في محيط العمل؟

\begin{tabular}{|c|c|c|}
\hline النسبة المئوية & عدد الأطفال & طبيعة العلاقة \\
\hline$\mu V_{.0}$ & $r$ & جيدة \\
\hline$\mu V .0$ & $r$. & معتدلة \\
\hline ro & $r$. & سيئة \\
\hline$\% 1 \ldots$ & $\Lambda$. & المجموع \\
\hline
\end{tabular}

لا شك أن علاقة الطفل بزملائه تلعب دورًا مهمًا في استمرار الظاهرة، و الجدول

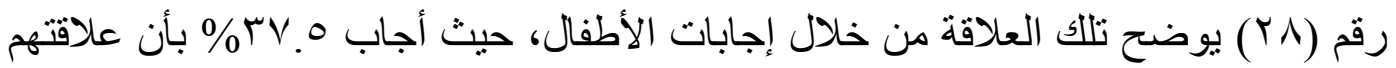
بزملائهم جيدة ويسودها التعاون، في حين أجاب ه.\% ب بأن علاقتهم بأقر انهم معتدلة أي وسط ليست محبة أو عداء، بينما من أجابوا بأن علاقتهم بالزملاء سيئة هץ\%\%. ونجد من الإجابات السابقة أن الفئة الأولى آثرت السلامة مع الزملاء سواء في المصانع أو السوق أو الثنارع؛ لكي يستمروا في عملهم، أو حتى يتجنبوا إيذاءهم واعتداءهم عليهم، في حين أن الفئة الثانية آثرت الحياد في التعامل، أي قصرو اتعاملهم مع زملائهم على علاقة العمل فقط، بينما اتبعت الثريحة الثالثة أسلوب العنف؛ حتى تصنع لنفسها مكانًا وسط الزملاء، وحتى يهابوهم ولا يحاولوا الاعتداء عليهم، ولعل هذه الفئة هي أقل فئة؛ حيث إن الغالبية من الأطفال تؤْثر السلامة حتى تستطيع أن تعول أسر ها.

\section{الآثار الاتاتجة عن عمالة الأطفال في الخرطوم:}

رغم أن ظاهرة عمالة الأطفال مستهجنة في كل أحو الها، فإن هنالك مَن اعتبر ظاهرة عمالة الأطفال لها العديد من الجوانب الإيجابية إذا ما توافرت لها البيئة الملائمة، ولكن الو اقع أثبت أن ظاهرة عمالة الأطفال ضارة للطفل؛ حيث إنها تعتبر انتهاكًا صارخًا لحقوق الطفل، وتؤثر على الطفل نفسيَّا ومعنويَّا وماديًّا. وفيما يتعلق بآتار عمالة الأطفال، فمنها: آثار ترتبط بالطفل بصورة مباثرة أو غير مباشرةٍ، بينما هناك آثار ترتبط بالمجتمع بصورةٍ مباشرة أو غير مباشرة، ومن هذه الآثار: 


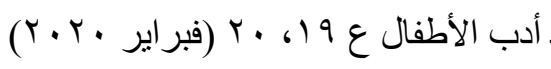
ظاهرة عمالة الأطفال في الخرطوم

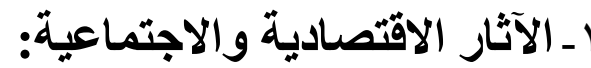

لا شك أن عمالة الأطفال تؤدي إلى بطالة البالغين، إلا أن هذا لا ينطبق على الظاهرة في الخرطوم لسببين، أولهما: أن بطالة البالغين موجودة فعلاً، و السبب الآخر أن معظم الأطفال العاملين منخرطون في مهن هامشية، وهي المهن التي تستهوي البالغين بسبب ضعف العائد و ما يتعرض له العاملون من معاملةٍ سيئة. ولكن التأثير الحقيقي لظاهرة عمالة الأطفال هو تأثير ها السلبي على عملية التنمية، حيث إن خروج الأطفال في سن مبكرة من المنظومة التعليمية من شأنه أن يؤثر سلبًا على الثروة البشرية للمجتمع، والتي سوف تضعف نتيجة خروج الأطفال من العملية التعليمية و عدم حصولهم على أي تدريب، وهذا من شأنه أن يضعف القوة التي سوف تلقى على عاتقها

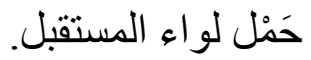
ومن القيم الخاطئة في المجتمعات التقليدية، الاعتقاد بأن انخر اط الطفل في سوق العمل من شأنة أن يكسبه مهارات، إلا أن الواقع أثبث فثل هذا الاعتقاد، حيث إن معظم الأطفال يمارسون مهنًا طفيلية لا تكسب الفرد آية مهار ات. ورغم تطرقنا إلى التحاق الأطفال بمراكز التدريب، فإن الواقع الذي لمسناه أن هذه المر اكز لا تؤدي دور ها بكفاءة؛ إما بسبب ضعف الإمكانات، أو بسبب عدم وعي أصحاب الأعمال بأهمية التذريب واستخدام الوسائل الحديثة في التصنيع. مما سبق نجد أن عمالة الأطفال في الخرطوم تؤثر بالسلب على رأس المال البشري وخطط التنمية الاقتصادية، وهي تأثيرات طويلة المدى لا تعيها أسر الأطفال أو المجتمع، فإذا كان عمل الطفل ضرورة مُلحّة للأسر في الوقت الحالى، فإنها لن تكون كذلك بالنسبة للأسرة أو المجتمع على المدى الطويل. أما فيما يتعلق بالآثار الاجتماعية السلبية، فمنها: حالة العزلة التي يعيشها الطفل نتيجة طول فترة العمل بعيدًا عن الأهل والأصدقاء، وكذلك حرمانه من ممارسة هو اياته المفضلة و اكتسابه سلوكيات سيئة نتيجة بُعده عن رقابة الأهل لفتراتٍ طويلة، ولعل أكثر التأثيرات سوءًا لظاهرة عمالة الأطفال، هي الآثار التي تنتج عن تعرض الأطفال للإيذاء البدني، والذي يترك آثارًا بدنية شديدة، وهذا يوجد في مهن منل: خدم المنازل و العمل في الشوارع، وإن كانت عمالة الأطفال في نطاق الأسر في نظر العديد من المحللين أقل أنواع 


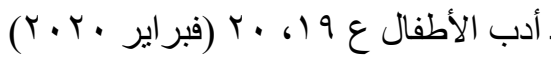
ظاهرة عمالة الأطفال في الخرطوم

وفي النهاية، نستطيع أن نستخلص أن الآثار الاجتماعية السلبية لظاهرة عمالة الأطفال كثيرة، ولن يكون آثار ها على المدى القريب فقط وإنما سوف تظهر على المدى البعيد بصورةٍ أكبر و أعمق. r ـ الآثار الصحية والتفسية:

تعتبر الآثار السلبية التي يتركها عمل الأطفال على صحتهم ونفسيتهم هي الأكثر تأثثرًا ودمارًا على المجتمع، ولا شك أن الإصابات التي يتعرض لها الطفل أثناء عمله تترك آثارًا سلبية على تطوره النفسي و البدني؛ حيث إن الأطفال أكثر عرضه للإصسابة، ولعل ذلك بسبب نقص وعي الأطفال أو قلة الحيطة والحذر من قِبَ الأطفال العاملين، بالإضافة إلى عدم معرفة الطفل بحقوقه. كل هذا من شأنه أن بدعم زيادة استخلال الطفل ماديَّا ومعنويًّا وبدنيًا، وفي هذه الدراسة نجد أن الزجر و الضرب الذي يتعرض له الطفل في هذه السن المبكرة يؤثر عليه بالسلب ويساهم في زيادة العدوانية لديه، كما أن هنالك مهنًا يتعرض فيها الطفل للإيذاء البدني و المعنوي ولا يستطيع أن يقر بذلك؛ إما لعدم إدراكه أو لخوفه من استهجان المجتمع، ولعل أكثر هذه الصور وضوحًا في قطاع خدم المنازل؛ حيث إن هذا المجال يتسم بالسرية من طرفي العلاقة. تُعد ظاهرة "أطفال الثوارع أو أطفال بلا مأوى" ظاهرة عامة؛ حيث إنها توجد في دولٍ كثيرة، وهي ظاهرة ضارة إذا لم يتم علاجها، وهنا سوف نتعرض لقصتان تتحدثان عن أطفال الثوارع في دولة نيجيريا: الأولى تُسمى "تعليم صبي المنطقة" والثانية "منزل الضفادع يُسمى بِرْكَة". 1 - تعليم صبي المنطقة:

ترجمة: د. نهى عبد الله خيرت، تأليف: طوني أوجونلوا، وهو مؤلفُ نيجيري له أكثر من 1 مؤلًَّا ما بين شعرٍ، ومسرحٍ، وقصة قصيرة، وروايات، وهو صحفي ينشر مقالاتٍ في مجلات نيجيرية مختلفة، ونم نشر بعض قصصه على إذاعة (BBC) في يونيو .$r \cdot 11$ (القصة: يُطلَق على أطفال الشوارع في نيجيريا "الأولاد"، وهم مجموعة من الأطفال بملكون قانونًا خاصًا بهم "قانون عرفي"، قد يمارسون العنف من أجل الحصول على "كيس حلوى"، ولهم رائحة تميزهم نتيجة وجودهم الدائم في الثارع، يعيشون مثل الحيوانات الضالة 


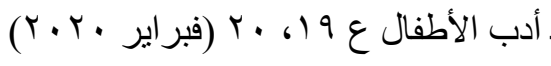
ظاهرة عمالة الأطفال في الخرطوم وينامون في أي مكانٍ أسفل الكباري في الحدائق العامة أو في مبانٍ تحت الإنشاء، ولكل

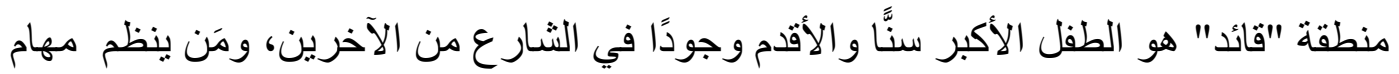

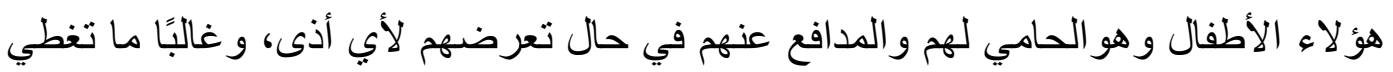
الندبات وجهه نتيجة تعاركه مع أطفال المناطق المجاورة.

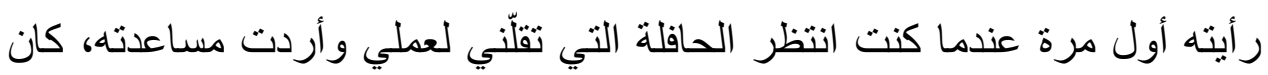
أصغر الموجودين، عمره لا يتعدى العشر السنوات بأية حال من الأحوال، وسنّه هذا لا يمكّنه من البقاء في الثنارع.

بدأ حديثه معي عندما اقترب مني ليتسول أثناء انتظاري للحافلة، وكان هذا منذ ستة أنشهر، في البداية بدأ يتوسل و هذه هي الطريقة التوسل في البداية ثم الاستيلاء على متعلقاتك

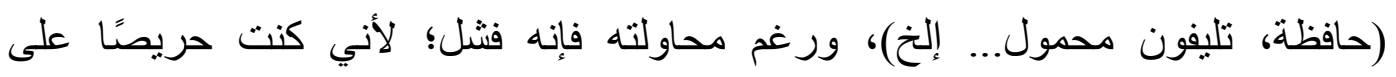
أغر اضي، خاصة و أن لي در اية بأساليبهر.

وبمرور الوقت، عرفتُ أن اسمه (صنداي)، عادتي أن أصل إلى موقف الحافلات

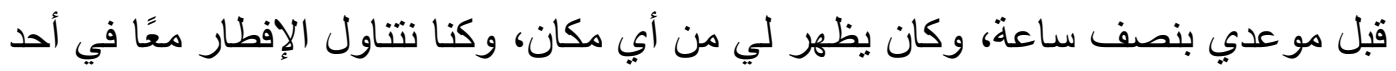

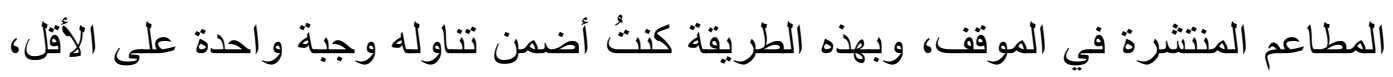
ومع تكرار جلوسي معه استطعتُ تكوين صورة كاملة عنه وعن حياته.

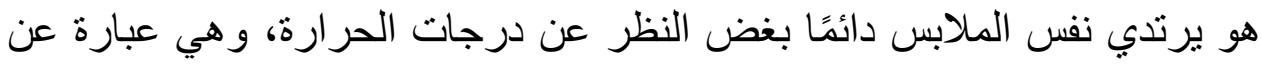

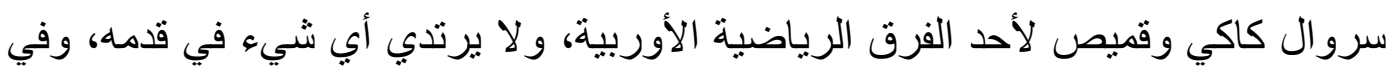

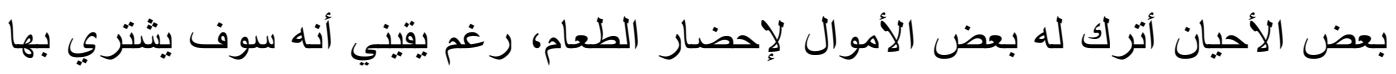

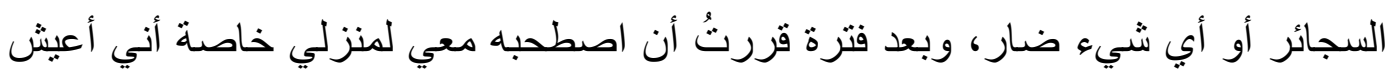
بمفردي، وقررت أن أحضره ليقوم ببعض الأعمال المنزلية وأعطيه مقابل؛ لكي يحيا حياة كريمة وتتغير حياته.

كانت محاولة إخراج طفل من تللك المنظومة "أطفال الثوارع" في مدينة مثل

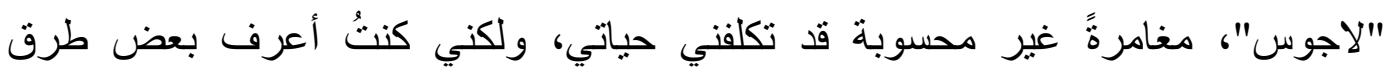

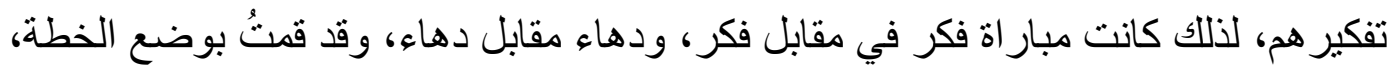

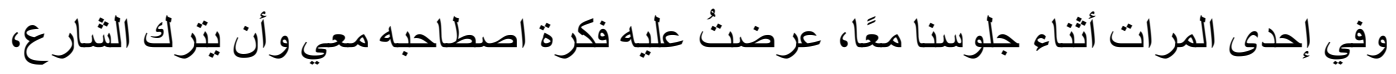

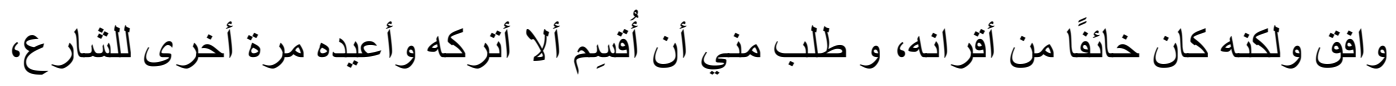




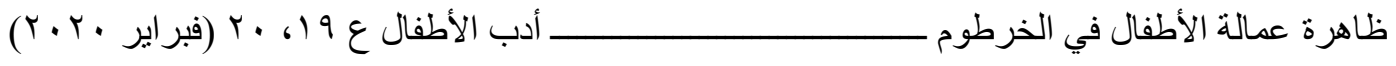
أقسمتُ له بحياة أمي التي رحلت منذ فترة، وفي المقابل طلبتُ منه أن يسمع الكلام ويكون

ولدًا مطيًا.

اتفقنا، وبعد أسبوع نفذت خطتي، كان يوم عطلة رسمية وهو يوم الجمعة، وجدته

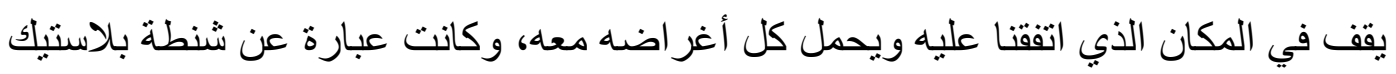

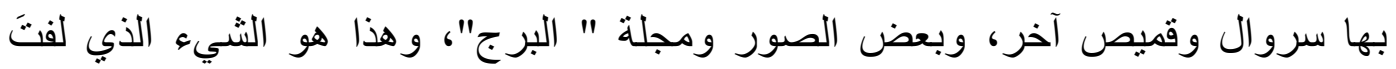

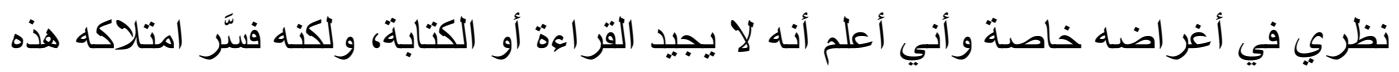

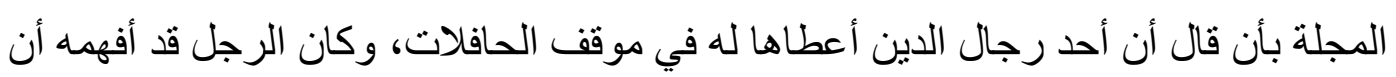

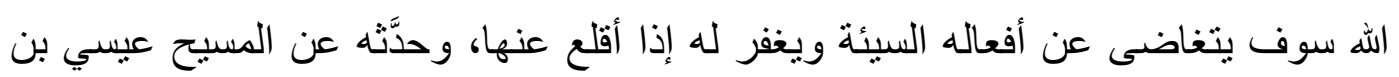

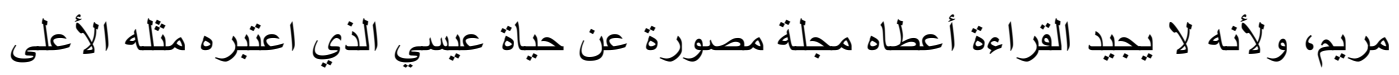

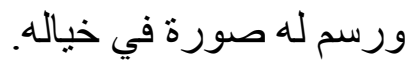

هذا الموقف جعلني أعيد حساباتي، لقد كنتُ أنظر إلبه باعتباره مجرمًا، أما الآن فأنا

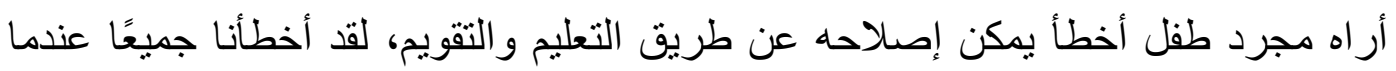

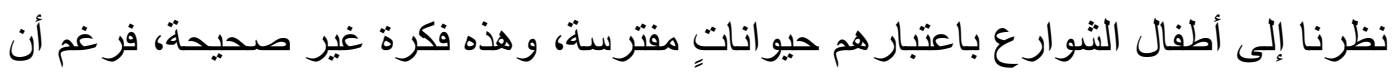

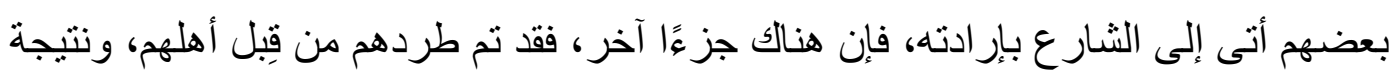
تفكير هم الطفولي وجدوا في السرقة والنهب و العنف وسيلتهم للبقاء في تلك الثوارع سواء لثناء بمفردهم أو من خلال جماعة، وهم يرون أنهم قادرون على حماية أنفههم، وإذا تم إلقاء القبض عليهم، لا تتخذ الثرطة ضدهم أي إجراء؛ خشية مواجهة أقرانهم من أطفال الثنوارع، مما ساهم في تفنشي الظاهرة. لاهن.

ـ قمتُ باصطحابه معي إلى منزلي بتاكسي في الجهة الأخرى من المدينة، كان أثناء الرحلة يتلفت كثيرًا ليستطلع ما حوله، وكانت الطرق مرصوفة والمنازل رائعة جميلة، وحراس البوابات برتنون زيًا موحدًا، وكان مثل طفل محلق في السماء، تركنا التاكسي ولهي

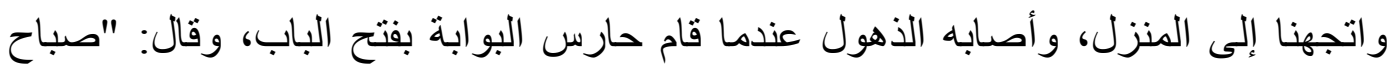

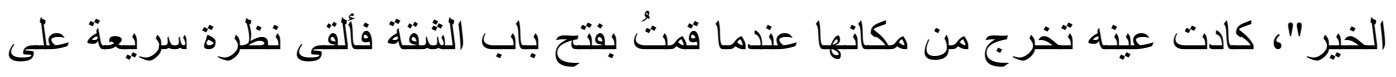

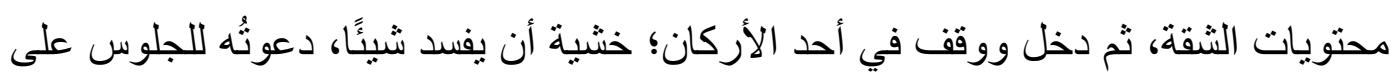

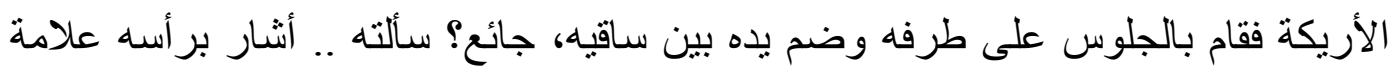




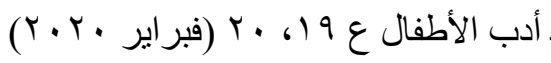
ظاهرة عمالة الأطفال في الخرطوم

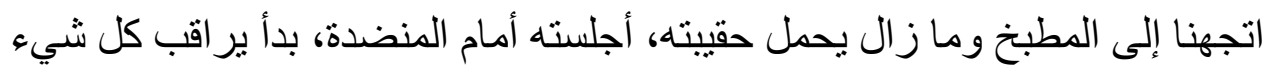

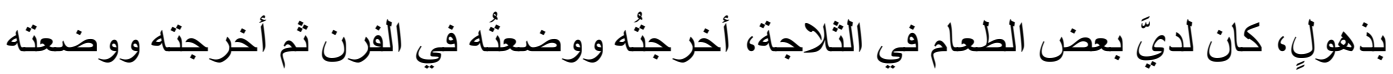
أمامه، كانت الأبخرة تتصاعد منه، نظر للطعام لبضع ثوانٍ ثم ما لبث أن انقض على لثلى الطعام

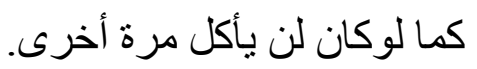

جلستُ أمامه و أشرتُ إليه بإصبعي أن يبطئ من تناوله للطعام، في قانون "أطفال

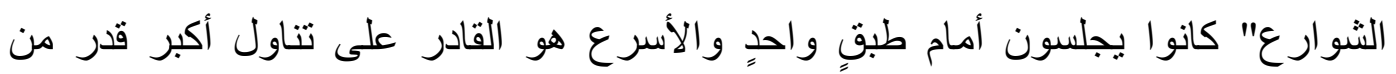

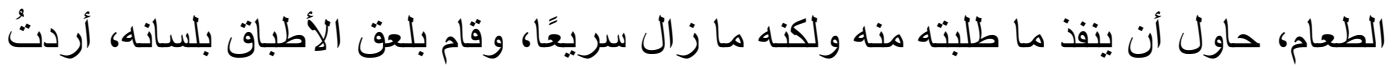

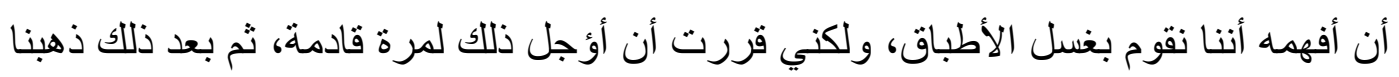
للاسترخاء، وقمثُ بإعطائه زجاجة مياه غازية، وحدق في التلفاز ، وكان يبدو أنه لم يرَ تلفازًا

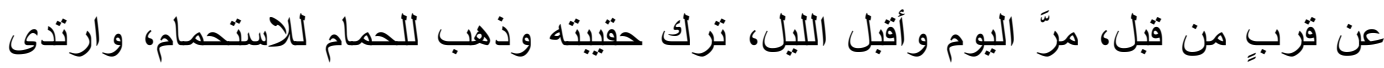

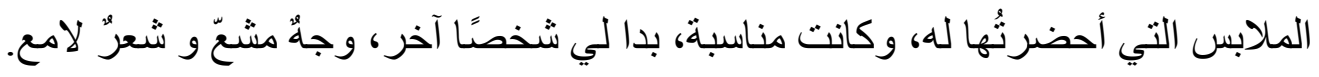

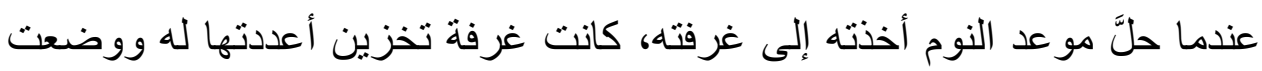

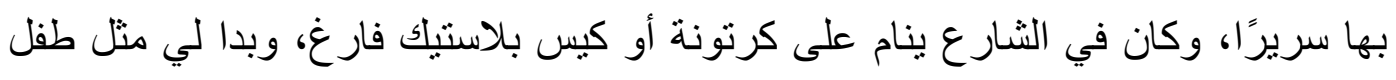

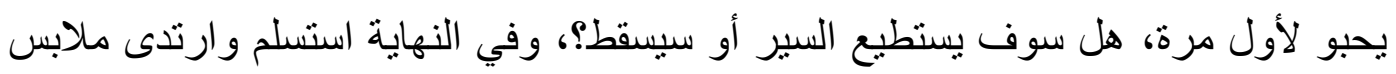
النوم التي اعتقد أنها ملابس خروج، في البداية تركته وذهبت إلى غرفنتي، لم أستطع النوم

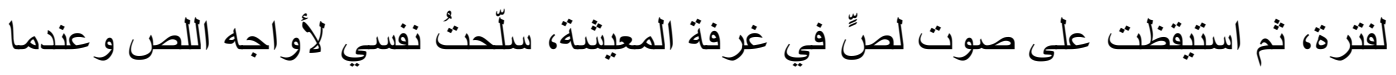

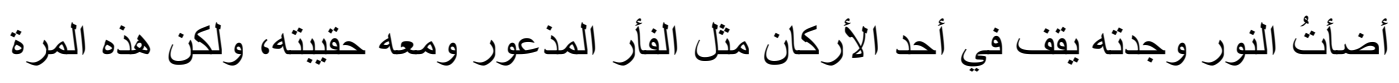

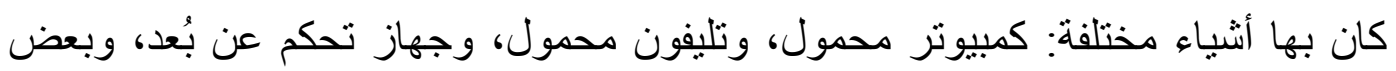

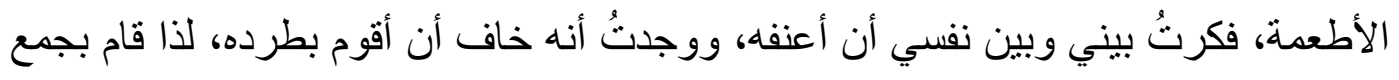

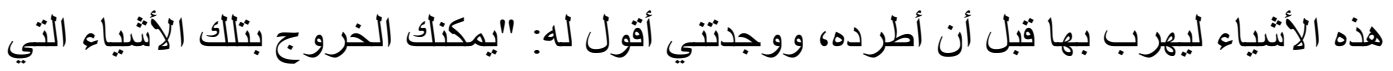

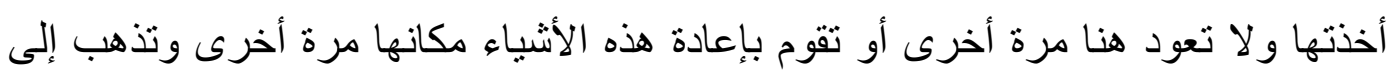

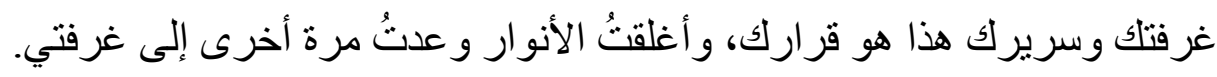

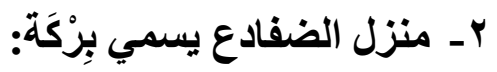

ترجمة: د. نهى عبد الله خيرت، المؤلف: أوكويسلي براين، وهو كاتبٌّ إفريقي ولِد في جنوب نيجيريا، وهو يهوى الكتابات الواقعية، ورغم أنه يملك الكثير من إلخيال فإنه يليرس القانون. 


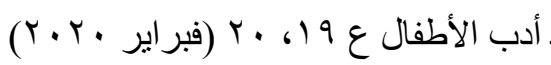
ظاهرة عمالة الأطفال في الخرطوم القصة:

أعرف أنك نشأتَّ في الشار ع، حدث بينكما توحّد، أصبحت جزءًا منه و أصبح جزءًا منك، رغم حداثة سنّك تأقلمتَّ مع حياة الثارع، فقدتَ أبيك و أمك مبكرًا، ووصفلكَ أقاربك "بالفأل السيئ"، كلما فقدَ أحد أقاربك شييًًا اتهموك بأنك السارق، و أنت تعلم أنك لستَ لصنّا أو سارقًا؛ لأن أطر افلك الدقيقة لا يمكنها فعل ذلك، لذا قررتَ الفرار إلى الثـارع وقمتَ بإخبار كل من يقابلك بأن أقاربكَ أشرار، ولم يفهم معظم الناس ما تقوله، خاصة أنك تتحدث "الإيبو"، في حين أن معظم الموجودين في المدينة مغتربون لا يتحدثون سوى الإنجليزية،

حتى الذين فهموك وصفوك بالكاذب "أجونو ا" طفل سيئ رغم أن عمرك لم يتعدَّ السادسة. لقد جبت الشوارع تبحث في صناديق القمامة عن بقايا الأطعمة والأرز المحترق وبقايا الزيت المتخلفة في علب السردين الفارغة، أما الخبز القديم المبلل بندى الصباح هو المفضل و الأثير لديك، شعرك باهتُ وفروة ر أسك مليئة بالتقرح ووجهك شاحبّ. بيوت الطيور في الأشجار نطلق عليها أعثاش، و الضفادع تعيش في برك المياه، أما أنت فليس للك بيتُ، تنام في الحافلات القديمة أو في المنازل تحت الإنشاء، وكانت الحشر ات تساهم في إزعاجك فلا تترك فرصة للنوم، وكنتَ تستيقظ مع بزوغ أثنعة الثمس؛ لكي تبحث عن طعاملك وتتمكن في البقاء على قيد الحياة. لقد تخطيت سن الطفولة وانتقلت إلى مرحلة المراهقة، وأصبح اسمك "تيجانا" بدلاً من "إيشانا"، ورغم أنك لم تعرف معنى الاسم فإن له صونًا كما لوكان اسمًا بطوليَّا، ومرت السنوات و استطعت تكوين مجموعة من الصداقات من أقرانلك من أطفال الثوارع، خاصة بعد أن تم إلحاقلك بأسرة مكوَّنة من أربعة من أقر انك من أطفال الثور اع، ورغم أنك كنتَ أكثر هم ذكاءً، لكن كان يجمع بينكم مصيركم السابق المشترك، وهي لم تكن عائلة بالمعنى الحقيقي، إلا أنك تمسكتَ بها لأنها وفرتْ للك الحماية و أشعرتلك بالعاطفة. لقد أصبحت رجلاً الآن، وبدأت تفهم أن المجتمع يحاسبك على أفعالك، و أهم ما تقوم به الآن كرجلٍ، وليس كطفلٍ، يجب أن تتظاهر بأنك لا تهتم بحياتلك السابقة إلا أنها ـ و لا شك ـ تحتل جزءًا كبيرًا من مشاعرك، لقد علمتلك الثوار ع ألا تُظهر مشاعرك. الآن تنظر في المر آة ولا تصدق ما طر أ عليك من تغيير، حتى إنك لفترة لا تصدق قصتلك السابقة التي ترويها، ولكن يجب عليك كتابتها ليستفيد منها الآخرون، لقد تغيرتْ حياتك من خلال علاقاتك، وكذلك أسمائك، كنتَ تُدعى "أوشنا" ثخ "تيجانا" والآن 


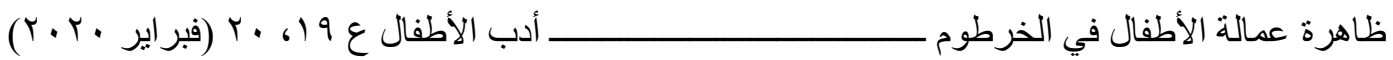
"زيكور ا"، يجب عليك أن تخبر الجميع أن بشرتك لم تكن لامعة كما هي الآن، وأنكَّ لم تكن تعرف من قبل "زيت جوز الهند"، وأن أهم ممتلكاتك كانت قلمًا متعدد الألوان وقصة لقطة زارتِ الملكة، وأن ممتلكاتلك الحالية من عقار ات لا تمثل للك شيئًا ولا تهمك. الآن وأنت تجتمع مع رجال الأعمال في مجال النفط، وتفوح منهم العطور النفّاذة، وبدأت تتخيل حياة هؤ لاء الأفر اد وتقارنها بحياتلك وتساءلت بينك وبين نفسك: هل يعلم هؤلاء الأشخاص أن الخبز القديم المبلل بندى النهار ألذّ عندك من البيض المخفوق؟! 